\title{
Gastón Gaínza: "el exilio es un aprendizaje que no termina"
}

\section{Por Carlos Sandoval García ${ }^{1}$}

Recepción: 20 de septiembre de 2015 / Aprobación: 8 de octubre de 2015

\section{Introducción}

U na mañana de 1982, la clase de Estudios Generales en la modalidad de Seminarios Participativos tenía una dinámica diferente. Veríamos una película italiana llamada Novecento (1976), la cual presentaba el surgimiento y auge del fascismo italiano, dirigida por Bernardo Bertulocci y protagonizada por Gerard Depardieu y Robert de Niro. Para un muchacho como yo, quien había sido criado en Paraíso, un cantón entonces semirural de la provincia de Cartago en Costa Rica, en donde los dos cines que existían usualmente ofrecían películas muy lejanas a Novecento, aquella experiencia era extraordinaria. Posteriormente, al finalizar la película, llegó un profesor a realizar un comentario y motivar la participación de los y las estudiantes. Los argumentos del profesor eran tan sugerentes como los de la película. Aquellos estudiantes escuchábamos atentos a aquel profesor que vestía guayabera, usaba anteojos y cargaba un maletín. Años después, supe que el profesor que había llegado a la clase era Gastón Gaínza Álvarez, esposo de una de las profesoras del Seminario, Iveth Inostroza Sotomayor, quien junto con Raúl Torres Martínez, Susana Trejos Marín y Susana Witman Stengel, conformaban el equipo de profesores.

Mi segundo encuentro con Gastón fue en la Escuela de Ciencias de la Comunicación Colectiva de la Universidad de Costa Rica. Don Gastón, como le decíamos, ofrecía un seminario en la, recientemente abierta, Licenciatura en Comunicación. Mis recuerdos, luego de casi 30 años, tienen presente el tono argumentativo de sus clases, las "prácticas de conocimiento", trabajos mediante los cuales se evaluaba el curso y, sin duda, una bibliografía novedosa, que nos invitaba a elaborar interpretaciones más elaboradas y densas sobre los procesos de comunicación, los discursos y su lugar en la sociedad.

Mis clases, organizadas a través de casos y prácticas, deben mucho a mi experiencia como estudiante del profesor Gaínza. Mi encuentro con Gastón me permitió, además, entrar en contacto con la obra de Mijail Bajtín, un autor que ha viajado conmigo todo este tiempo y que leí por primera vez en el seminario que él nos ofreció. En el curso de Gastón habíamos leído algo del libro La cultura popular en la Edad Media y en el Renacimiento. Con los años,

1 Costarricense. Doctor en Estudios Culturales por la Universidad de Birmingham, Inglaterra. Profesor de la Escuela de Ciencias de la Comunicación Colectiva e Investigador del Instituto de Investigaciones Sociales, ambos en la Universidad de Costa Rica. Correo electrónico: carlos.sandoval@ucr.ac.cr 
yo continué leyendo los libros del llamado "Círculo Bajtín" del cual también formaban parte Valentin Voloshinov y Pavel Medvedev. Bajtín y sus colegas contribuyeron a trascender la distinción entre lengua y habla, y abrieron nuevas alamedas para comprender el lugar del otro en la conformación del sí mismo. Bajtín ha estado muy presente en mis trabajos sobre migraciones.

La convocatoria de la revista Cuadernos Inter.c.a.mbio sobre Centroamérica y el Caribe, publicada desde el Centro de Investigación en Identidad y Cultura Latinoamericana (CIICLA), del cual Gastón es cofundador, se debe mucho a la complicidad de la Dra. Soili Buska Harju, Directora de la revista, a quien agradezco mucho esta oportunidad. Soili y yo conversamos durante tres sesiones con Gastón durante este año $2015^{2}$ quien muy generosamente nos compartió su tiempo y sus recuerdos, incluidos aquellos que aún duelen.

La biografía de Gastón puede ser leída como una serie de desplazamientos forzados y exilios. Hijo de padres vascos, crece en Chile y, como él mismo anota, "mi casa era una frontera", pues las costumbres y el habla de la casa no se correspondía con el que se practicaba en el Santiago de Chile de las décadas de 1930 y 1940, cuando Gastón era un niño y luego un adolescente. El Golpe de Estado de 1973 lo obliga a dejar Chile y llega a Costa Rica. Una mañana de marzo de 1974 adquiere el que sería su primer colchón para dormir en Costa Rica en un negocio que estuvo ubicado en donde ahora se encuentra el Outlet Mall en San Pedro de Montes de Oca y horas más tarde ofrecería su primera clase en la Escuela de Estudios Generales. Entre 1982 y 1984 vive en Costa de Marfil y al regreso, como él mismo ha escrito y retomado en esta entrevista, encuentra otra Costa Rica; son los tiempos de la crisis económica y los conflictos armados en Centroamérica. Dicho de manera muy apretada, Gastón ha estado aprendiendo a vivir en distintos contextos. Su boina, su gusto por el vino, la guitarra y el canto, sus guayaberas son huellas de esos desplazamientos.

En la trayectoria académica se pueden distinguir al menos tres preocupaciones principales. La primera de ellas, la que le lleva a iniciar estudios de doctorado en la Universidad Complutense de Madrid, es el análisis de modalidades del castellano de la América Latina. A su llegada a Costa Rica, facilita cursos sobre Castellano -no español, desde luego- de América Latina y Castellano de América Latina. La semiótica es una segunda gran preocupación que se nutre de lecturas durante su estancia en Costa de Marfil. Gastón ofrece un curso titulado Tópicos de semiótica, en donde los discursos sociales, no exclusivamente construidos a partir del lenguaje verbal, son discutidos a partir de diversas perspectivas teóricas y metodológicas. Las identidades culturales constituyen una tercera preocupación presente en el trabajo académico de

2 Mi agradecimiento para con Ada Soto Loáisiga, estudiante de Psicología de la Universidad de Costa Rica, quien transcribió el audio de las sesiones de la entrevista. Mis gracias también a Karina Fonseca por su lectura cuidadosa. 
Gastón. Quizá sea en este tercer tópico en que su biografía y sus interrogantes se entrejen con mayor intensidad.

Las contribuciones de Gastón ilustran muy bien cómo las ideas y los modos de trabajo viajan de un territorio a otro y enriquecen tanto a las sociedades de acogida como a los recién llegados. Ello no ocurriría si las personas no se desplazaran y los locales no se abrieran a considerar nuevas cosmovisiones. Sin este dinamismo, se corre el riesgo de idealizar los saberes locales y tradicionales como los únicos posibles. El intercambio es vital para el trabajo científico y artístico; si no, corremos el riesgo de cocinarnos en nuestra propia salsa.

Gastón nació en el año 1933, es decir, cumplió 82 años en abril de este año 2015. Por esas casualidades de la vida, una mitad de sus años los ha vivido en Chile y la otra mitad en Costa Rica. Sea este un homenaje agradecido para él y para tantas personas que la violencia y el exilio les trajo a Costa Rica provenientes, especialmente, de América del Sur y de otros países de América Central. Las artes, las ciencias y las humanidades que se practican en Costa Rica deben mucho a ellos y ellas.

Carlos (CS): Quienes trabajamos en migración hemos descuidado mucho la experiencia de desplazamiento por razones políticas de muchas personas sobre todo de América del Sur hacia Costa Rica. Hay muy poco escrito sobre ello y en ese marco pues la invitación a rememorar la trayectoria y contribuciones de un intelectual como Usted, Gastón. Una inquietud adicional, le decía a Soili hace unas semanas, que, usualmente, las discusiones sobre las Ciencias Sociales son sobre puntos de vista teóricos o metodológicos, pero hay muy poca referencia a las biografías de las personas que practican las Ciencias Sociales o las Humanidades. Las referencias que hay a esas biografías pues son en general de personas del Norte. Uno conoce entrevistas con un historiador muy conocido o con una persona de los Estudios Literarios, con una persona de Psicología, pero pocas veces uno encuentra relatos de quienes desde América del Sur llegaron a Centroamérica. En este marco y en el contexto de la convocatoria de la revista Cuadernos Inter.c.a.mbio sobre Centroamérica y el Caribe me parecía muy interesante el poder escucharle a usted. Ojalá pues sea el principio de varias entrevistas con personas que tanto han contribuido a la Universidad de Costa Rica.

Gastón (GG): Sí y sobre todo que algunos estamos por tomar la nave de que habla Antonio Machado, que nunca retorna, entonces eso hay que, de alguna manera, tenerlo muy en cuenta. Yo tuteo a Carlos, Soili, porque él tuvo la desgracia de ser alumno mío y de enseñarme, tener que enseñarme porque yo tuve que aprender mucho con él y me remito mucho en el diálogo a él por esa razón, porque surgió entre nosotros un nexo, además de afecto debido a que él también tuvo la mala suerte de ser alumno de mi esposa en Estudios 
Generales. Sí, entonces, por esa razón me dirijo más a él que a usted, pero estoy naturalmente consciente de que estoy hablando con ambos.

Soili (SB): No se preocupe.

GG: Nací en Santiago de Chile un 6 de abril de 1933. Mis padres habían emigrado años antes, antes de la Guerra Civil, por razones políticas también porque antes de la dictadura de Franco, que fue la dictadura más cruel, estuvo la dictadura de Primo de Rivera (1923-1930) que, en España, la llamaron "dictablanda" porque no era tan dura, pero tuvo alcances en el País Vasco de donde son oriundos mis abuelos, tanto paternos como maternos. Se ensañaron con la gente, entonces eso provocó que hubiera movimientos migratorios previos a lo que vendría después con la República y la Guerra Civil. Eso lo explico para que entiendan mi doble carácter de no ser nacido, pero sí criado en una casa española.

CS: Yo tenía la inquietud, perdón que lo interrumpa, de si usted había nacido en España y muy chiquito se fue a Chile o había nacido en Chile.

GG: Claro, el problema es que nací en Chile pero, mi casa, como lo describo en algún articulejo por ahí, mi casa era una frontera. De la puerta de calle para afuera, yo tenía que ser chileno porque, si no, los pillastres [pillos] de mis años con los que jugaba, se reían de mí. Como llegué con mi acento a la secundaria, que no era el acento chileno típico, uno de los pillastres, ahora llaman bullying a esto, me bautizó como "Chacha" porque estaba de moda Chachita, la actriz, niña actriz mexicana porque a ellos les sonaba cuando yo hablaba "shh, shhh, shh, shh" la sibilante que los chilenos no pronuncian casi. Entonces, a mí me enfadaba, y les andaba rompiendo la cara a cada rato porque me decían Chacha. En el fondo me sentía tratado como marica y, en esos años, con la homofobia reinante, era intolerable.

En esas circunstancias ingresé a la primaria, por supuesto llegaron las abuelas, abuelos no, no llegaron. Las abuelas, ambas viudas, llegaron y las abuelas; una, la materna, era realmente mi cómplice. Como yo vivía en la casa de mi abuela materna, cuando iba a la casa de la abuela paterna lo que hacía era ponerme un rosario en la mano y rezar en unos reclinatorios que ella tenía. Ella fue la que determinó que yo la primaria la hiciese con los Escolapios, con los frailes escolapios que eran españoles en Chile y que eran terribles porque esos castigaban con varilla, o sea, con castigo físico.

No contenta con eso, yo le agradezco después de todo porque con los Escolapios aprendí una serie de triquiñuelas, una serie de formas de eludir el poder, de cómo se evadía el poder. Y, posteriormente, ella, no contenta con ese primer aprendizaje en secundaria también trazó mi destino a un instituto que era controlado por el clero, pero que estaba en ese momento en manos de presbíteros diocesanos o sea curas que no eran de orden religiosa sino que eran de los presbíteros españoles de la falange española. Así que, en mi secundaria, claro, había profesores civiles en su mayoría, pero los curas que mandaban eran de la falange española. Estoy hablando de los años de 1941 
y 1942 para que ustedes me comprendan lo que quiero decir; estamos en plena Segunda Guerra Mundial, ha sucedido ya lo de España entonces estos curas de la secundaria, se empeñaban en sanarnos, querían sanar a mi padre y nunca lo consiguieron, pero mi madre iba cabeza baja a las reuniones que citaban para sanarnos de que hubiésemos tenido la enfermedad de los rojos en España, el tormento de haber sido rojo [comunista].

Entonces, mi primaria y mi secundaria fueron de un niño piadoso que hacía maldades como decía antes, las cuales las aprendí a hacer con los Escolapios y que los Escolapios toleraban, yo creo, y que tenía naturalmente las cosas de todo chiquillo chileno de esos años. Un ansia por ejemplo, de arrancarnos [salirnos] de clase porque había empezado la moda de los rotativos de cinematografía entonces, había funciones permanentes y llegaban las noticias de la guerra y todo eso era como ver películas. Íbamos escapados a ver largas sesiones porque duraba una hora cada exhibición y seguía. Con el precio de una entrada uno se podía quedar horas ahí viendo la misma cosa hasta aprendernos de memoria casi los relatos de las noticias, era simpático. Ese tipo de maldades hacíamos pero, efectivamente, el régimen docente del instituto fue un régimen muy estricto aparte del condicionamiento religioso, era sin embargo de un alto nivel humanista y científico.

Eso permite tal vez entender el por qué cuando yo termino la secundaria en 1949, ingreso en 1950 a Ingeniería Química y claro, en eso todavía fallaban las condiciones de la Educación Secundaria de Chile, pues no había orientadores, psicólogos, como hay ahora. Aquí [en Costa Rica] por ejemplo, eso está resuelto hace años. Entonces yo hice el bachillerato en Humanidades o Letras y en Biología. Humanidades incluía, naturalmente, Historia, Filosofía e idiomas. Biología incluía Química y Matemáticas. Yo escogí Química porque había tenido un buen profesor y había aprendido por amor a la enseñanza de él mucha química, sobre todo la química orgánica era lo que me apasionaba y que se trataba en los últimos años de la secundaria. Entonces yo decía: "Bueno, si me ha ido bien en Química, tal vez una carrera como esa". Mi madre no tenía formación más que la formación básica, mi padre trabajaba de una manera brutal porque siempre fue un emigrante entonces tenía que trabajar muy fuerte de manera que siempre lo necesitasen; no se preocupaban mucho de lo que me podía hacer. La hermana de mi madre, mi tía, trabajaba también, tenía que trabajar porque la abuela estaba en la casa. La abuela no sabía nada de nada pero sabía todo de todo; era como una bruja vasca y me enseñó a cocinar, entre otras cosas. Me contaba historias oriundas del pueblo de Munguía en Vizcaya y las leyendas, todas las leyendas míticas. Pero ellas no sabían qué podía estudiar yo. Fue mi tía la que a mediados de ese año de 1950 se pregunta y me pregunta a mí “¿Por qué te va tan mal?" Porque me iba mal en álgebra, en trigonometría, en realidad el álgebra superior a la que me enfrenté y que había que usar ya la regla de cálculo y todas esas cosas que en esos años, estoy hablando de 1950, eran como las computadoras de 
ahora. En el instituto [secundaria] no habíamos manejado nunca esas cosas, entonces yo le explicaba que en la clase no entendía nada. Había otra clase de Geometría muy grata, ahí me iba bien. En Química me iba bien, pero tampoco química todavía era mi fuerte.

Como era una ingeniería lo que yo estudiaba, el fuerte eran puras ciencias matemáticas entonces, mi tía me dice: "¿Por qué no cambias la mención en matemáticas y haces lo que tú haces en las tardes?" Yo al atardecer, me encerraba en el cuarto que llamaba mi salón violeta y escribía versos. Había conocido a una vecina y estaba enamorado de ella y entonces le escribía esos versos que cobardemente nunca le hice llegar, como le sucede a todo adolescente.

Y entonces, a raíz de esto le puse atención a lo que decía mi tía, hablé con unos pillastres compañeros y había tenido yo la buena suerte del año 1949 cuando terminaba el instituto de incorporarme, por casualidad porque un amigo me llevó, a la Academia de Letras del Instituto Nacional que era y sigue siendo el establecimiento de secundaria más respetable de Chile, no solo de Santiago, de Chile entero. El Instituto Nacional es donde se han formado muchos presidentes de la República previos al golpe de Estado de 1973 y que existía desde el siglo XIX; desde casi los albores de la independencia de Chile. En esa Academia de Letras yo había hecho mis pinitos de llevar colaboraciones, había un profesor que lo dirigía que era de un espíritu benévolo y al mismo tiempo de estímulo que era imposible decirle que no cuando le pedía a uno... a ver, tráigame tal cosa, tráigame esta idea... Y yo llegaba, me daba el tiempo y llegaba con la tarea; señor Boero se llamaba este profesor. Boero que fue famoso dirigiendo la Academia de Letras de ese instituto. Yo busqué al amigo que me había llevado a la Academia de Letras, quien estaba repitiendo unos cursos y que iba a dar el bachillerato en Letras y me puse a estudiar con él y sacamos los dos el bachillerato en Letras e ingresamos los dos a Filología en la Universidad de Chile. Allí se llamaba Pedagogía en Castellano en esos años, pero era Filología y ese fue el inicio de un cambio fundamental en 1951 y es cuando yo cumplo en abril 18 años de edad.

Al cumplir los 18 años de edad se ha producido en mí una gran transformación que entre 1949 y 1951 tiene como proceso, primero que nada, el alejamiento de la creencia religiosa y, segundo, las lecturas, un mundo variado de lecturas de todo tipo de novelas. Yo salgo de las revistas de historietas para precipitarme ya en las novelas, de Balzac hasta Dostoievski y entrando a la carrera de Pedagogía uno de los cursos oficiales es Literatura universal. Me deslumbro con todo lo que yo me había perdido de leer y lo empiezo a leer.

En una de esas me llega, estando en ese primer año, un pequeño folleto que se llamaba, simplemente, El Manifiesto Comunista. Entonces, me dice mi amigo, quien, por esas cosas de la rueda de la fortuna que no se explica uno, vino a terminar sus días aquí como profesor de la Universidad de Costa Rica y de la Universidad Nacional. Carlos Santander Tiraferri se llamó mi amigo, él 
me dice: "Oye, ¿por qué no vienes a unas reuniones que tenemos nosotros los días viernes después de las cinco de la tarde para que entiendas esto?" Bueno, así inició mi ingreso al Partido Socialista de Chile, a la juventud del Partido Socialista de Chile que era un partido, para que se formen una idea rápida, como el Partido Acción Ciudadana aquí, juntaba de todas partes, como [el partido político] Podemos en este momento en España, era un conglomerado de tendencias y cosas, pero, mantenía una cierta línea del Partido Socialista dentro de la juventud. Nosotros fuimos cooptados realmente por un grupo trostkista, que partía de sentar con mucha claridad que el estalinismo era una cosa horripilante, horrible que no podíamos estar en esa órbita el Partido Comunista de Chile ni convertir el Partido Socialista en parientes de ese estalinismo y que el verdadero momento de la Revolución había sido cuando Lenin le entrega el poder a los Soviets en la segunda Revolución no en la de febrero-marzo si no que en la de octubre-noviembre de 1917 y eso es lo que este movimiento interno del Partido Socialista decía, es decir, hay que volver a la comuna de París, hay que volver a los movimientos orgánicos desde las bases, desde las masas, desde la gente y así fue el inicio también de mi condición política. Curiosamente, hubo elecciones en el año 1952, al año siguiente, y había dos candidatos. Perdón, había cinco candidatos en esa elección, pero, dos candidatos del partido socialista. Uno era Salvador Allende que de alguna manera, estoy hablando del año 1952, representaba el Partido Socialista de los orígenes digamos; era más social demócrata soviético digamos. El otro candidato del Partido Socialista era un exgeneral que anunciaba barrer con una escoba la corrupción que se había formado en los gobiernos anteriores previos a esta elección.

Y este grupo en que yo estaba, a pesar de hacer los análisis en que todos participábamos, tenían su línea trazada: "No, hay que apoyar a este general, él no tiene la fuerza que los jóvenes que podemos estar a su lado, entonces nuestro apoyo". Por desgracia, el general Ibáñez del Campo, así se llamaba, ganó las elecciones y significó que la otra parte del partido que se había quedado con Salvador Allende resultáramos expulsados, incluido yo, todavía siendo de la juventud en el partido. Y esa expulsión me alejó del partido durante años, pero me permitió dos cosas: terminar los estudios con menos tarea política, dedicarme más intensamente a los estudios y postergar las cosas políticas a lecturas.

Pero, ya entonces, aprovechando precisamente esto me puse a leer en serio a Marx y a Engels junto con la preparación de mis trabajos en la universidad y mi tesis de grado que había terminado. Yo egresé en el año 1956, terminé todos los cursos, pero la tesis no la terminaba nunca. Tenía un tema de tesis de grado que era sobre un novelista chileno homosexual que había escrito un libro sorprendente sobre un cura; el libro se titulaba Pasión y Muerte del cura Deusto, que tenía nombre vasco. Ello era extraño porque este escritor chileno no tenía ascendencia vasca, más bien su familia originaria era gallega asturiana pero no vasca. Esta tesis me hizo darme cuenta de cosas que yo ya estaba 
aprendiendo por los libros que leía de Marx, Engels y los libros complementarios de autores, como Lenin o posteriores.

Me daba cuenta de que la formación social en que uno surge tiene una fuerza reproductora y es reproducción social en el fondo y que esa fuerza reproductora se llama programación social de los comportamientos y que, claro, entre los comportamientos adquiridos de esa manera estaba la homofobia, la intolerancia que yo sentía pero de una manera visceral. Intolerancia considerarlos como nos habían dicho siempre los curas y los frailes, considerarlos degenerados, enfermos, entonces en la confesión de la tesis yo me debatía entre mi antiguo mundo y el mundo nuevo que se me había abierto tanto en la universidad como en mi aventura política inicial, de modo que la tesis salió por fin porque, si no, no podría haber conservado la ayudantía que había logrado. Allá las ayudantías se ganaban por oposición o sea no era nombrado así porque un profesor te invita a ser ayudante, sino que se presentaban los papeles, los documentos. Yo gané la ayundantía en el año 1956. Fue una ayudantía primera, había primera, segunda y tercera; yo gané de un golpe la primera en circunstancias de que había compañeros míos que tenían incluso mejores notas que yo, que habían ganado ayudantías antes, como este amigo mío Carlos Santander que había ganado una ayudantía de tercero, de tercer grado.

Pero, el Decano nos dijo en el año 1958: "Al que no se gradúa este año no le voy a cortar el rabo, le voy a cortar la cabeza". Tuve que terminar mi famosa tesis porque a todo esto, además de consolidar mi plaza de ayudantía, había finiquitado mi dependencia de mi casa materna, la había finiquitado y quería independizarme. Tenía una novia y decidimos casarnos para lo cual yo tomé un horario de trabajo en la secundaria que era diurno y nocturno. Yo recuerdo que alcancé en cierto momento hacer más de 60 horas semanales de clases y ganar lo suficiente como para decir ya podemos casarnos, cosa que ocurrió justamente ese año, 1958, que yo terminé, presenté mi tesis, me gradué y me casé en el mes de diciembre... Perdón no, me equivoqué, yo me había casado ya en el año 1957, en 1958 nació Rodrigo, mi hijo mayor que me acompañó aquí al comienzo del exilio junto con mi hija Maite que eran de ese primer matrimonio. Mi primer matrimonio fue en diciembre de 1957. Mi primogénito nació en diciembre del año 1958 y en enero de 1959 fui nombrado profesor de la Universidad Austral de Valdivia, como profesor visitante inicialmente y después ya llegué a ser catedrático de esa universidad.

El año 1959 nos trasladamos con la que entonces era mi esposa y el hijo mayor. Luego nacieron tres hijos más, el segundo murió muy pequeño, Maite que está viva y Álvaro que es el menor de ese primer matrimonio mío que ha venido aquí varias veces, pero que no estuvo al comienzo conmigo. Los que vinieron conmigo al exilio fueron Rodrigo y Maite, los mayores. Álvaro, sin embargo, es ahora el más próximo a mí porque además es profesor de la Universidad de Humanismo Cristiano. Álvaro estudió en la Universidad de Arte y Ciencias Sociales (Arcis), donde fue alumno y discípulo de Tomás Moulian. 
Álvaro es muy cómplice mío en la actualidad. Ese matrimonio, el primer matrimonio, terminó el... puedo decir que en el año 1970.

En mi vida, en la Universidad Austral de Chile, hay varios episodios que tienen significado, que tienen que ver fundamentalmente con las prerrogativas que surgen en la función docente universitaria, en la función académica, tengo necesidad de sacar un posgrado, es una urgencia, no es tanto institucional en el caso mío pero, sí yo me doy cuenta que no puedo contentarme con lo que hasta ese momento tengo un grado en Filología. Entonces la Universidad Austral, por haber sido yo nombrado Secretario General de la misma muy al comienzo de mi carrera, cargo que asumí en 1963 y hasta 1966, Secretario General de la universidad y que fui compañero de trabajo del rector Félix Martínez Bonati, también filólogo que también había sido ayudante de la misma cátedra que yo, en grado primero antes que yo, obtuve de la universidad una beca para hacer el posgrado y yo escogí la Universidad Complutense de Madrid porque la tesis que en ese momento estaba preparando para un eventual posgrado, para la cual ya había reunido materiales durante algunos meses sobre todo en vacaciones, era una revisión de la gramática de la Real Academia Española que en ese momento era la oficial, que era del año 1931. Entre otras cosas, yo había descubierto en esa gramática de la Academia Española, robos intelectuales a Andrés Bello y a la gramática que Andrés Bello estudió en Santiago de Chile en 1860 y tantos, y entonces mi trabajo iba por ese lado. Mi maestro en Chile, de quien que tengo que hablar también un poco en su momento, mi maestro en Chile era un manchego, y como manchego se parecía a don Quijote de la Mancha, el personaje que nunca existió, pero que tenemos en la cabeza metido desde que leímos El Quijote. Un manchego que era un hombre muy probo, que fue contralor, el último contralor de la República española, en Barcelona, cuando ya Madrid estaba prácticamente asediada por los fachas. Él era filólogo y salió al exilio a Chile; allá fue profesor mío en el Pedagógico. A esos estudiantes que él tuvo, que éramos todos compañeros de curso, nos pidió que lo acompañásemos en una misión que le habían encomendado, fundar la Facultad de Filosofía y Letras en la Universidad Austral de Chile en Valdivia. Yo a Valdivia la conocía de nombre nada más, yo sabía que existía en Chile una ciudad que se llamaba Valdivia, los primeros tenían que irse con él en el año 1958 y el segundo grupo, en el cual estaba incluido yo, en 1959. De esa manera, yo llegué a la Universidad Austral, gracias a ese maestro Eleazar Huerta.

Y este maestro Eleazar Huerta cuando supo que Félix Martínez me había conseguido esta beca y que yo estaba trabajando, porque él sabía en lo que yo estaba trabajando, pues ya había publicado un primer artículo en la revista de la Universidad Austral, titulado La Clasificación de Oraciones de Andrés Bello, en el que estoy diciendo justamente cómo la academia ha usado esa clasificación sin citar a Bello porque es un americanito, el típico golpe de autoridad de la corona española, me dice don Eleazar: "Gaínza mire usted-siempre me ha tratado de usted- yo le voy a dejar una carta para Rafael Lapesa -él es un 
hombre que no fue republicano pero sí ayudó mucho, después he sabido, a los republicanos- lleve una carta mía en que yo le voy a decir lo que usted está haciendo, pero se la doy cerrada Gaínza para que él sepa que la carta está sellada, es confidencial".

Entonces cuando yo llegué a Madrid, estoy hablando del año 1968, es el mes de mayo de Madrid. Está terminando un año académico y va a comenzar el próximo, pero yo quería poder viajar a reconocer, conocer mejor dicho los pueblos de mis antepasados, de mis abuelos y de mis padres. Entonces, como venían las vacaciones, yo saqué la cuenta: llego en mayo, es término de curso, los profesores están en la tarea ya de poner notas y tuve la entrevista, la primera entrevista con don Rafael Lapesa, le entregué la carta, él muy solemne me saludó, me dio la bienvenida: "¿De dónde viene usted?" -"De Chile, de la Universidad de Chile". Me dice: "vuelva usted el viernes" -"Perfecto". Y el segundo encuentro que fue prácticamente el mismo día, fue con don Américo Castro. Para él, yo llevaba una carta de mi compañero Guillermo Araya, que en ese momento era el Decano de la Facultad, en sucesión de nuestro maestro, Eleazar Huerta. Guillermo Araya había escrito un libro sobre Américo Castro, libro que, evidentemente, se publicó después y por Gredos en Madrid. La carta decía que le enviaba el manuscrito por encomienda y que cuando lo recibiera viera si podía hacer algo por publicarlo. Américo Castro se sintió feliz de esto, ya estaba bien viejito y entonces a mí me asumió. Me dijo: "Mientras tú estés aquí" -ese sí me tuteó- "mientras tú estés aquí vendrás todos los días jueves a tomar el té conmigo, llegas a las tres y te vas a las seis" -era metódico-. Hasta que se puso enferma su señora.

Esto era el mes de mayo, durante el verano yo viajaba de manera [que] cuando salía de Madrid tenía que hacerlo antes del jueves y después del jueves, porque el jueves era sagrado durante los meses de mayo, junio, julio y agosto. Era el pleno verano, yo en Madrid tomaba trenes e iba por ejemplo, a Euskadi, a Salamanca, hacía mis viajes, pero tenía que volver rápido porque los jueves era este encuentro y don Américo me recibía, me enseñaba sus libros, me iba diciendo: "Ya, ya tengo listo el libro de Araya, va a salir en Gredos. No te preocupes, dile a Araya cuando le escribas que todo está bien entonces". Me enseñaba de todo ese hombre, o sea me enseñó cómo escribió su gran obra, que es una obra fundamental para la España Republicana. Él se había exiliado, pero era profesor en California, y de ahí se jubiló y volvió con el régimen todavía vivo pero, como venía de catedrático de la Universidad de California en San Diego, entonces evidentemente no podían perseguirlo ni fastidiarlo; lo dejaron vivir en Madrid.

Un día me invita a un restaurante de cierto lujo en Madrid, ya la señora estaba enferma, ya no podía salir, no podía levantarse, tenía un problema. Entonces me dice: "Mira vamos a ir a comer" -como se le dice a la comida de mediodía se dice comer, no almorzar como aquí- vamos a ir a comer a un restaurante" -“Claro, lo que usted diga don Américo", le respondo. Y llegamos al restaurante, 
nos sentaron en la mesa, a él que era un viejo venerable, estoy hablando año 1968, él tenía más o menos 83 años, más o menos esa edad, porque él nació en 1885 si mal no me acuerdo, serían 83. Pero tenía su apariencia de hombre mucho mayor, digamos en este momento yo me vería más joven que él entonces. Estamos en eso comiendo con toda ceremonia, cuando aparece un grupo de hombres jóvenes, jóvenes como yo en ese momento que se sientan en una mesa al frente, alborotadores, alborotadores que hablaban en voz alta.

Entonces, yo estaba mirando, estaba sentado en la mesa de modo que veía ir y venir a los que sirven, a los mozos, como se dice en España, meseros como se dice aquí. Veo que viene el jefe de los meseros con un libro rápidamente hacia nosotros entonces, yo digo: "Ah van a hacer firmar a don Américo", pienso yo y me quedo expectante y no; se van a la mesa de enfrente para que firme el cantante Rafael, quien era uno de esos jóvenes. Lo hacen firmar y el restaurante estaba feliz porque había llegado Rafael, que además era cantante de Franco.

Claro, le cantaba a Franco ese tío [expresión coloquial y usualmente despectiva], en el año 1968 estamos en pleno Franco, mis cartas llegan todas rotas. Las que salen de España a Chile, llegan abiertas a Chile y los chilenos en ese tiempo no tenían dictadura entonces le ponían ceremoniosamente: "Esta carta fue abierta antes de ingresar en el correo chileno" y las cartas que yo recibía también, sobre todo las de mi padre llegaban trajinadas. Por lo demás, sabíamos que tenía que ser así, ya yo no era nada ingenuo a esas alturas del partido. Entonces, el problema es que claro, termina el mes de julio, se pone un poco mala la señora, la señora de don Américo y él me dice: "Mira Gaínza, nos vamos a ir un tiempo este verano. Carmen necesita estar más tranquila, pero, ¿dónde te vas a quedar tú definitivamente?" Ya estamos hablando del mes de julio, ya las clases iban a comenzar, entonces le digo: "Entiendo que me van a admitir en el Colegio Superior Hispanoamericano" -"Ah yo he ido ahí a dar charlas, cuando yo llegue yo te localizo ahí" -"Perfecto". Y esa fue mi última entrevista con él porque él se siguió quedando allá y después de unos meses también murió él; murió la señora y murió él.

Ya estamos en el año escolar de 1968, empiezan las clases a fines de septiembre. Don Rafael Lapesa me ha recibido ya varias veces también en la Facultad y me dice: "Usted va a formar parte del grupo de trabajo que tiene tal y a sus compañeros los va a conocer pronto". El curso que él dictaba era de Gramática histórica, es una eminencia este profesor Lapesa, una eminencia. Sigue siendo una eminencia en los estudios históricos del castellano, sobre todo los verbos, las conjugaciones del castellano las manejaba y me dice: "Ponte a trabajar, sigue trabajando en esta tesis que me interesa mucho".

Otro profesor cuyo nombre estaba tratando de recordar ahora pero, si no lo recuerdo ahora, la próxima vez lo traeré fresco. Ya, don Alonso Zamora Vicente, un rojo, que se había mantenido rojo y que nunca había salido al exilio, 
pero había pasado, se había tragado todo el franquismo, era el profesor de Dialectología y ese me tomó como un, como un amigo más que como alumno entonces. Él me hacía preguntas, me decía: “¿Y cuántos [rojos] hay en Chile?". Yo le decía: "Varios, tenemos una casa republicana en Santiago" -"Háblame de eso, háblame de eso". Era un verdadero cómplice fueron los dos profesores míos don Rafael Lapesa y Alonso Zamora Vicente. Ah, y la esposa de Alonso Zamora Vicente, quien también era una fonetista destacada que era asturiana y que era una mujer muy especial... ellos eran rojos, se mantenían ahí.

Llegamos al mes de diciembre y a fines de noviembre hubo en París una reunión del exilio republicano, año 1968. No se olviden ustedes de que el año 1968, a mediados de año, fue el 68 de París y en París están algunos de los que luego van a ser los dirigentes jóvenes del Partido Socialista Obrero Español, como Felipe González por ejemplo, y hacen una reunión con el gobierno en el exilio para hacer un cambio y llegar a un pacto con el Partido Comunista Español y eso se sabe en Madrid. Naturalmente, en Madrid, las autoridades toman medidas y nos cierran la Facultad, cerraron tres facultades: Derecho, Economía y Filosofía. Se cierra la Facultad que va a ser reabierta en enero y a la cual había que ingresar a la vez con todos los documentos al día, pasaporte, el documento de residencia, todo, todo al día totalmente; la policía en la puerta, barricadas. Un día de estos que yo voy a comer en el restaurante de la universidad, entraron los grises a caballo, ese es el mes de enero del año 1969.

Yo les comentaba que vino el momento en que yo egresé del doctorado en Filología Hispánica con todos mis cursos aprobados, faltaba la tesina y la tesis. La tesina era un trabajo que me dijo Rafael Lapesa que se podía ya dar por hecho porque yo llevaba ese artículo sobre la clasificación de las proposiciones de Andrés Bello y que me serviría ese mismo artículo, que era uno de los primeros que publiqué, me serviría como la muestra de la diferencia teórico metodológica que había entre la gramática del venezolano, que por cierto publiqué en Chile, y la gramática de la academia madrileña. Entonces, tenía que preocuparme, me dijo, de la tesis.

Yo le presenté mi plan de tesis, que tenía que hacer posteriormente, en el curso del año 1969-1970 con él. Tenía que hacer una cuestión de seminario, de avance de mi tesis para que yo pudiera graduarme, él sacaba cuentas de que en enero o febrero del año 1970, así de fácil. Pero, entonces ocurrieron dos cosas, la Universidad Austral de Chile, que era la que había facilitado mi beca para estar en España con la mantención incluso de mi salario, autorizaba que yo permaneciese un año más, que es más o menos una norma universitaria en los países nuestros, que son dos años para hacer un posgrado salvo que haya algo razonable suficiente como para prolongarlo. Entonces yo podía contar con ese segundo año, pero llegó a Madrid la que era mi esposa en el mes de junio, 
cuando ya estaba llegando el verano. Años después, que conste, dos años después, me enteré de que la razón por la que había ido no era la que me parecía a mí que era querer verme porque habíamos estado separados más de un año ¿no? Yo había llegado en mayo de 1968 a España y esto estaba ocurriendo en el junio de 1969.

El asunto es que con ella y con unos amigos que yo había hecho ahí viajamos por España. La llevé al pueblo paterno, digamos, era un guía en Vizcaya y en fin, y regresamos a Chile. Ah perdón me saltaba, ella me traía, me llevaba una carta de Guillermo Araya en que... -quien era, en ese momento, el Decano de la Facultad y compañero mío de curso- en que me decía: "Mira Gastón, tenemos elecciones en 1970, a comienzos, hay que elegir el Decano y el único candidato que no sea de derecha y aceptan eres tú. Eres el único que aceptan sobre todos los demócratas cristianos, ninguno de los demás nombres de la gente de izquierda es aceptado, pero tú tienes que decidir realmente si prefieres terminar tu posgrado o venir y terminarlo acá para asegurar que la Facultad no cambie de manos". Teníamos en la Facultad muchos proyectos en ese momento que sabíamos que la derecha iba a eliminar, como el de Dialectología, que no le interesaba naturalmente a la derecha un trabajo así. Además, en Literatura, teníamos profesores marxistas que estaban abriendo una nueva forma de lectura con el estructuralismo soviético, antes de Mijail Bajtín, antes de Yuri Lotman con el estructuralismo soviético que llegaba así en oleaditas pequeñas a Chile.

Entonces, consideré que mi deber en ese momento, por la misma edad que tengo, tengo 36 años cumplidos, voy a cumplir 37 entonces, decido regresar a Chile, decido regresar a Chile y me encuentro una situación académica muy confusa. Regresamos en el mes de agosto, a comienzos de agosto, de 1969, días antes se había producido el alunizaje, el único alunizaje que ha habido de humanos en la superficie de la luna, se había producido en julio de ese año 1969.

Chile en el año que yo había estado ausente había cambiado enormemente, se había intensificado la lucha de clases a unos niveles que eran, para mí, insospechados. Nunca había visto tan claro, el enfrentamiento era ya totalmente polarizado y así estaba la universidad también y, en efecto, me acomodé en la universidad y ganamos la elección y me nombraron Decano en marzo de 1970.

En el mismo año, 1970, en septiembre, con una intensa lucha, gana Salvador Allende la presidencia, pero eso es meses después de que yo ya era Decano. Mientras tanto, a nivel íntimo, personal, digamos de mi intimidad, yo advierto, ya en Madrid notaba muchos indicios, que mi pareja ya no era mi pareja, yo sentía. Ella insistía en negar cualquier cosa hasta que, en el año 1971, efectivamente, ella tuvo que reconocer que se había enamorado de otra persona, cosa que a mí me pareció en ese momento doloroso, pero normal porque como se lo dije a ella no iba yo a blandir la navaja como mis antepasados brutales de la novela 
realista española e iba a empezar a degollar a medio mundo, no. Lo que hice fue llamar a la otra persona a quien yo conocía, más aún éramos compañeros de trabajo, más aún éramos camaradas del mismo partido. Lo invité con la que era mi mujer a tomar un café en un restaurante de Valdivia y yo expuse las cosas. Dije yo he sabido, me parece que eso es normal, sucede, que ha habido entre ustedes una relación y como estas situaciones tienen que resolverse, yo pongo a disposición de ustedes lo que yo pueda hacer para que si ustedes quieren seguir como pareja sigan y yo me hago cargo de los hijos y todo se arregla de esa manera sensata. Esto es el año 1971, mientras tanto el gobierno me había nombrado a mí en la Comisión Nacional de Investigación Científica y Tecnológica de Chile (CONICYT), que era un organismo regulado desde la presidencia de la República en ese tiempo, que en Chile era la Democracia Cristiana, que reunía a la gente de todas las áreas del conocimiento, naturalmente de los ámbitos académicos del país para cubrir las diferentes necesidades del país. ¿Aquí hay algo parecido verdad?

CS: Sí.

GG: El hecho es que por designación de la Presidencia, yo llego como representante de Lingüística, además llevo una carta muy importante en la manga y es que estamos terminando el Atlas Lingüístico del sur de Chile, el primer atlas lingüístico que se hacía en Chile y estaba por entrar a imprenta ya. $Y$ entonces yo quedo nombrado para todos los proyectos que significan esta exploración lingüístico-etnográfica, eso lo quiero subrayar, lingüístico-etnográfica que empezaba en el sur de Chile desde la provincia de Cautín, hasta la provincia de Chiloé Continental, no llegaba hasta el extremo sur de Chile que es la provincia de Magallanes, sino hasta Chiloé Continental, pero que era una extensión muy importante porque ahí cohabitaban también etnias aborígenes con la población mestiza y con la población criolla.

Así que yo estaba en medio de toda esta maraña de cosas, era Decano, tenía que viajar por lo menos una vez al mes hasta Santiago para asistir a reuniones de la CONICYT, dar informes, y tenía el -voy a usar una expresión tanguera- el corazón destrozado, destrozado porque en el fondo yo amaba a mi esposa entonces, pero al mismo tiempo entendía que no porque yo la amase ella no tendría que realizar su vida como quisiese. El asunto es que resolvimos, por lo tanto, en el año 1971 y aquí termina la parte íntima que es importante que la haya recordado porque tiene que ver con un quiebre significativo de mi existencia. Resolvimos en 1971 separarnos, viviendo bajo el mismo techo porque, por razones económicas también, entre otras cosas, porque ella no aceptó juntarse con su nueva pareja. Estaba en esa tremenda duda terrible no porque me amase, sino porque había una cosa, la cosa familiar, los hijos, todo eso la reclamaban y ella... entonces, no se resolvió. Tuvimos que resolverlo de esa manera, vamos a seguir viviendo juntos pero cada uno con sus cosas. 
Llega el año 1972, ese fue un año terrible porque la derecha había orquestado toda una campaña contra el gobierno de Allende para desestabilizarlo con apoyo de Estados Unidos con el Departamento de Estado, como luego se demostró. Durante el año 1972, se llegó al desabastecimiento prácticamente total en las grandes ciudades de Chile. Los comerciantes que eran en su mayoría de derecha acapararon los bienes de consumo y los tenían guardados porque mientras tanto, la derecha obtenía dinero de Estados Unidos y les compensaba las no ventas. Ese mecanismo se usó también con los transportistas, a quienes se les pasaba su dinero para que no llevaran mercancía de un sitio a otro, se llamó la huelga de los camioneros y cuando salía algún camionero que no era de esa mafia, a ese camionero o lo mataban o le despedazaban el camión. El clima de 1972 en Chile fue terrible.

Mientras tanto, en la CONICYT había avanzado muy intensamente y quiero que en esto pongan atención porque he escrito sobre esto ya más de un artículo, lo he mencionado en más de un artículo quiero decir, no ha sido el tema del artículo sino que lo he mencionado. Habíamos avanzado en un plan de renovación escolar y educacional de Chile que llamamos la ENU, era la sigla para designar a la Educación Nacional Unificada. "E", "N", "U”; ENU. Educación Nacional Unificada que significaba que a partir del gobierno de Allende en adelante, Chile iba a tener un sistema educacional que iba a empezar en la cuna y que iba a terminar en la tumba. Que todos los chilenos iban a tener siempre la posibilidad de estar educándose, de tener institutos de educación para adultos, para adultos demasiado mayores, pero siempre atendidos con un criterio educacional, la idea naturalmente básica de este proyecto estaba en Pablo Freire que había llegado a Chile por los años setenta. Pablo Freire fue el gran impulsor de esta tarea en Brasil y su eco en Chile dio origen a este proyecto de educación. Y este sí, este proyecto en mi opinión fue el que encolerizó a la derecha chilena, la derecha chilena no podía consentir un proyecto educacional que significase, primero, que se le escapaba de las manos el control de la educación, que la derecha lo tenía desde la colonia naturalmente y, segundo, que implicaba un aumento de la conciencia social en todo el país. De modo que, el año 1972 fue un año en que todos los días despertábamos con la idea de la inminencia de un Golpe de Estado. Un general que habían nombrado para el Estado mayor, que era de apellido Pinochet, le había jurado lealtad: "No, presidente, tranquilo usted, aquí no va a pasar nada" - decía.

Esto más o menos en noviembre o diciembre de 1972. La universidad estaba conmocionada, la derecha de la universidad, las facultades que dominaba estaban paralizadas, no volvieron en marzo de 1973 a clases. Volvimos solo las facultades que estaban en nuestras manos, que fueron curiosamente la de Ciencias y Matemáticas, cuyo Decano, el doctor Álvarez de Araya, brillante matemático chileno, llegó al exilio a Costa Rica y en su casa viví cuando yo llegué pero, estoy adelantando eso porque está muy encima todo. Estamos en el año 1973, Álvarez de Araya se niega a cerrar su Facultad, Agustín Cullel, quien 
llega a Costa Rica, se niega a cerrar la facultad de la cual era él decano, la Facultad de Arte y Educación. Y Gastón Gaínza se niega a cerrar la Facultad de Filosofía y Letras. Son las tres facultades que funcionan, pero hay profesores que siguen dando clases en las otras. Por ejemplo, en Medicina hay un profesor que no era de izquierda, pero ayudaba de una manera increíble al proceso pensando que no era, como decía la derecha, un nido de comunistas, no. En esa convulsión ellos también rompieron de esa manera el paro decretado, pero, siguieron pasando los meses, la intensificación fue cada vez más ardua. Mi hijo mayor, Rodrigo, se había incorporado, incluso contra mis deseos, pero, era muy menor él todavía, tenía... voy a sacar la cuenta rápidamente, en el 1968 cumplió diez años, en 1973, 14 años, 14 años entonces...

Rodrigo se había incorporado en el Movimiento de Izquierda Revolucionaria (MIR), en la juventud del MIR. En una conversación con la que había sido mi mujer, estábamos separados aunque vivíamos juntos, yo le hice ver que era conveniente que Rodrigo saliese de Valdivia y que la familia de ella, que era mucho más grande y que eran todos de derecha, pudiera recibir a este niño. Entonces, con una conversación así logramos que Rodrigo saliese en el segundo semestre porque, en ese momento, él estaba en el cuarto de secundaria, allá eran seis de secundaria, para que siguiera cursando en Santiago el resto.

En esta situación ocurrió el Golpe, fue un 11 de septiembre. Entregamos la Facultad a la patrulla militar que fue a desalojar a los que quedábamos en la universidad ese 11 de septiembre alrededor de las 11:30 de la mañana. No nos hicieron nada, sino que nos dijeron que nos fuésemos a casa y escuchásemos los partes permanentes que difundía la emisora que ya era la emisora militar. Allende habló por última vez a las 9:10 de la mañana más o menos ese día y después esa radio la bombardearon, fue el último reducto y el último discurso que ha sido difundido incasablemente en discos, en películas, en documentales, ese discurso de Allende, muy conocido que termina diciendo: "Sigan ustedes sabiendo que, mucho más temprano que tarde, de nuevo se abrirán las grandes alamedas por donde pase el hombre libre, para construir una sociedad mejor".

Lleno de incertidumbre yo volví a casa, mi ex mujer fue a buscar a la hija que estaba terminando la primaria en un colegio alemán, del cual ella también era profesora, era profesora de Filología, de Castellano.

\section{CS: ¿Esa es su hija Maite?}

GG: Maite. Y el menor, estaba muy pequeñito, el menor tenía ocho años, ya estaba también en la primaria pero en el Colegio de los Salesianos. El asunto es que quedó desarticulado el partido, yo hasta el momento del Golpe había formado parte del comité regional del partido en la Comisión de Control y Cuadros. Yo era el encargado de la educación política regional del Partido Socialista de Chile, que tenía su sede capital en Valdivia, la ciudad de Valdivia, pero que cubría desde Chiloé hasta Valdivia porque Cautín ya era otra regional. Por 
lo tanto, yo sabía que todas las listas habían caído en manos de los militares, además que los partidos habían sido infiltrados por agentes de los servicios de inteligencia militares de las diversas ramas así que no fue... Hubo un parte militar -por ahí del día 24, me parece, 25 de septiembre-que obligaba a todos los profesores de las universidades a volver a los lugares de trabajo.

A partir del lunes 24 de septiembre se tenía que presentar todo el mundo a los lugares de trabajo. Yo me presenté el 24 a asumir mis funciones que no existían, nada más que a ver las caras porque a todo esto llegó otra persona interventora de parte del gobierno provisional militar, del gobierno regional provisional militar que se había instalado en Valdivia, así como el Rector, que era de derecha, había, naturalmente, entregado su lugar a un coronel que había llegado y se hizo cargo de la rectoría pero el Rector seguía ahí supervisando, en todo caso se quería que no apareciera ningún civil en las universidades.

A mí me pasó lo mismo en la Facultad, las secretarias estaban aterrorizadas, faltaron los que habían sido ya hechos prisioneros y los estudiantes que faltaron estaban en la cárcel, a quienes luego iban a matar, después de esta fecha 24 de septiembre. Yo a la sazón era Director del Instituto de Filología de la universidad y me fui a mi oficina del Instituto donde tenía mis libritos y mis cosas. El lunes 24 , el martes 25 y el miércoles 26 de septiembre a las tres de la tarde me hicieron prisionero, como les digo yo sabía que eso tenía que ocurrir. Esto significó pasar por momentos de mucha... muy desagradables que no me gusta volver a recordar, de manera... Ustedes entenderán que no es sencillo que lo hagan a uno prisionero y que quede incluso uno prisionero en un campo militar porque eso era mucho más riesgoso que la cárcel, donde estaban también los presos, no políticos digamos. En la cárcel, entraban abogados y salían abogados, la Cruz Roja, pero en un recinto militar estar prisionero no era nada de favorable. Nos enteramos los que estábamos ahí, porque entre ellos había estudiantes, estudiantes míos que en una madrugada se los habían llevado en grupo, esto fue más o menos por el 30 de septiembre y no volvieron. Efectivamente, tiempo después yo supe que los habían matado en las afueras de Valdivia, donde mataban a mucha gente.

Cuando esta situación terminó para mí fue en el mes de diciembre en que quedé con arresto domiciliario, o sea podía volver a mi casa, pero tenía que presentarme a firmar a la fiscalía militar periódicamente, al comienzo cada dos días, tres días y después una vez a la semana.

En enero de 1974, muere Ramón Sotomayor, el suegro de Carlos Santander que a todo esto se había casado en Valdivia. Carlos se había casado en el año 1971 en Valdivia y el suegro era el director de la Escuela Normal y murió. El suegro era masón y radical, era un buen hombre, entonces como yo lo conocía, había estado en su casa varias veces fui a la Fiscalía y pedí autorización para ir al funeral que era en otro pueblo, no en Valdivia, en un pueblo cercano que se llama Gorbea. Gorbea que es un nombre vasco curiosamente 
y me dieron entonces un salvo conducto; cuento esto porque para que vean ustedes que yo no podía moverme, no tenía libertad de movimiento, no podía salir del perímetro de la ciudad.

Entonces fui al cementerio de Gorbea donde incluso hablé, una despedida en que participaron varias personas. Yo también hice una despedida recordando la condición de este maestro ejemplar que había sido y era el director de la Escuela Normal y terminó este acto, fuimos a la casa de unos parientes próximos del fallecido.

Entre los parientes que estaban ahí, estaba la hija de Ramón, a quien decíamos Muchi, y su prima. Carlos Santander estaba asilado en la Embajada de Italia en Santiago... Muchi llorando se acercó a mí y me dice: "Mira, de Carlos no sabemos nada, está vivo pero está dentro de la Embajada y cada vez llega más gente"; era un desastre. Entonces yo le digo: "Mira no sé, yo tampoco, qué va a ser de mí" y en eso se acercó la prima de Muchi que la ve tan llorosa y entonces... que me conocía a mí, pero nos conocíamos así distantes; era Iveth. Entonces, Iveth le dice a Muchi delante de mí: "No te preocupes porque yo te voy a ayudar en todo lo que sea en Santiago, si quieres te quedas unos días más". Esa misma noche, Iveth volvió a Santiago, andaba con sus padres porque la madre de Iveth era hermana del fallecido por eso ella es Inostroza Sotomayor.

En el funeral, Iveth y yo nos vimos de nuevo, yo la había conocido a esta chica, a Iveth, en el matrimonio de Muchi con Carlos, ahí la había conocido porque ella incluso hizo un número de la familia, de las cosas que se hacían, las presentaciones en las fiestas de matrimonio, de modo que no éramos desconocidos, pero esa vez sí hubo una cosa más densa de conocimiento porque nos unía un dolor, una situación social dolorosa porque ahí me enteré de que Iveth era militante del Partido Socialista en Santiago. Le dije a Muchi: "Lo que dice tu prima es importante, tienes que tener mucho cuidado porque en este momento todos somos sospechosos de algo...". -"No, no, si yo sé cuidarme" -muy cortante me respondió Iveth.

Esto tiene que haber sido por ahí del 7 de enero de 1974. El día 12 de enero tengo que presentarme yo a la Fiscalía militar como tenía que hacer periódicamente para firmar y señalar que seguía ahí. Me recibe con mucha sorna un fiscal que era uno de estos muchachos recién egresados de Derecho seguramente y tenían una resaca, pero de muerte porque se notaba que en las noches bebían como trogloditas entonces, con una gran resaca me dice, hablándome como si yo fuera un peón absolutamente, que estaba en libertad condicional entonces yo le pregunto, como había que hacerlo: "Perdone señor ¿qué significa estar en libertad condicional?" Entonces me dice él: "Si yo fuera vos -y me agregó unos epítetos de las indecencias de palabras que usan los chilenos- me iría hoy mismo de aquí porque te vamos a volver a agarrar en menos de una semana si te quedais", usando el voceo chileno, te quedais, no te quedás ni te quedas, sino que te quedais. 
Bueno, yo me fui a casa inmediatamente, tomé lo poco que podía tener reunido y ya en la casa no quedaba nadie porque la que había sido mi esposa se había ido con los hijos a Santiago donde el hermano que era Coronel de ejército, médico, muy importante porque ese Coronel de ejército luego lo ascendieron a General porque ese fue el que revisó a Allende el 11 de septiembre para verificar si estaba muerto o no, tanto mando tenía.

Era una manera de estar muy seguros. Claro, este hermano de la que había sido mi esposa no tenía ninguna simpatía conmigo ni, naturalmente, con mi hijo mayor, porque mi hijo mayor estaba involucrado ya en la cosa. Entonces mi hijo mayor no estaba ahí sino que estaba con otros parientes de ella en Santiago, pero por lo menos estaban ahí en Santiago. Así que yo tomé mis cosas el 12 de enero y me fui al autobús que hacía el trayecto de Valdivia a Santiago, trayecto que duraba entonces 12 horas, ahora creo que dura 10 horas y media y a las cinco de la tarde empezaba el toque de queda, ya había que estar adentro del autobús, el autobús salía a las siete de la tarde, o sea, que dos horas en un autobús cubierto con una capa militar, ahí iban y venían, y nos revisaban los militares a cada rato los papeles y todo haciendo un control. A las siete salimos ya con toque de queda rumbo a Santiago a donde llegué a las siete de la mañana del día siguiente, el 13 de enero. Lo primero que hice naturalmente fue hacer una llamada telefónica a un concuño mío, que siempre me había ofrecido ayuda. Él estaba casado con una hermana de la que fue mi esposa.

Él me dice... yo le digo habla fulano "¿Podemos conversar?" Entonces me dice... me da un punto de referencia, me dice tal. Inventa una cosa para que yo me dé cuenta, la librería esa está en Huérfanos con tal parte, la calle Huérfanos con la calle Teatinos creo que era. Entonces yo tomo nota y me dirijo de la parada del autobús a esa dirección y él estaba esperándome allá entonces me dice: "Toma tus cosas" -él andaba en un vehículo- ¿te voy a llevar a donde tú vas a vivir" -era su casa pero tenía un ático, era una casa que tenía dos plantas y un ático y en ese ático estaba un hermano de la que fue mi esposa que era de izquierda, con el único que yo tenía un trato amable, que había sufrido unas quemaduras horribles, lo habían torturado y lo tenían guardado. Este concuño era cuñado de él y concuño mío. Lo tenía escondido ahí y yo también me quedé ahí. Entonces me dijo él: "Mira, tú tienes que salir de aquí inmediatamente que suspenden el toque de queda y desapareces de aquí y tienes que llegar un minuto antes que comience el toque de queda que en Santiago empezaba a las...". Es que es verano en Santiago, era de día a las ocho de la tarde; está totalmente de día oscurece en verano a las diez de la noche. Entonces tenía que llegar un minuto antes de las ocho y salir un minuto después o dentro del primer minuto en que suspenden el toque de queda y desaparecer.

Pude ir a la casa de mis padres. Mi padre todavía estaba vivo, pero mi padre era un hombre... mi padre era un anarquista, un anarquista, pero como buen anarquista no reconoció nunca filiación ni nada pero era anarquista de corazón o sea era anarquista. Mi madre seguía los pensamientos de él. Nos 
saludamos, yo les dije estoy bien, pero no sé cómo se llama esa calle en que estoy, no tengo teléfono de manera que yo voy a venir aquí, madre aquí traigo mi ropa sucia mañana vengo a buscarla a una hora cerca del mediodía. "Ah sí" -respondió ella, qué sé yo. Los españoles en eso son pa' dentro en situaciones así, no preguntan nada, no quieren saber nada de nada. Todo como que era mundo normal, todo sucedía sin que hubiese nada qué lamentar y de esa manera iba yo como a las 2:00 de la tarde, 2:30 de la tarde entrada y salida. Además, la casa de mis padres estaba en una especie de condominio que no era un condominio, era casa de capas medias más bien bajas, de gente trabajadora, pero en la esquina había una comisaría de carabineros que ya se había convertido en cuartel militar, de manera que yo tenía que llegar a la casa, pasar frente a esta comisaría de ida y salida con un sospechoso halo de poder infundir sospechas, o sea, de crearle sospechas pero, felizmente nunca pasó nada, sino que por ahí, por el día 30 de enero, llego yo a hacer esto, saber cómo estaba mi madre sobretodo porque mi padre ya se había desentendido mucho del asunto. Se juntaba con otros españoles y bebían mucho, estaban bebiendo de una manera desaforada entonces. Me preocupaba mi madre, que ella se tranquilizase, me preocupaba a mí yo le decía. Cuando ese día creo que era el 30 de enero, me dice: "Hijo, te llamaron por teléfono” - ¿Quién, cómo?” -le interrogué -"Sí, me dice, te llamaron ayer y yo respondí que tú no estabas en la casa, pero que estabas en Santiago porque era un señor de Costa Rica" - ¿De Costa Rica?" -“Sí, se llamaba algo Azofeifa”. El único Azofeifa de Costa Rica que me suena es un poeta que yo había estudiado, a Isaac Felipe, -¿Y qué le dijo usted madre?". Entonces mi madre me dice: “Le dije que tú venías mañana a las tres de la tarde". Entonces me dijo que iba a volver a llamar mañana a las tres de la tarde. Entonces al día siguiente yo estuve ahí poco antes de las tres, a las tres en punto sonó el teléfono y la voz inconfundible, que después para mí fue inconfundible, la voz de Isaac Felipe me dice: "Gaínza vaya usted cuanto antes al Consulado de Costa Rica en Santiago que hay una carta para usted porque lo necesitamos, ya las clases van a comenzar aquí y lo necesitamos porque usted va a ser profesor en la Escuela de Estudios Generales de la Universidad de Costa Rica".

En diciembre de 1973, cuando yo aún estaba prisionero, dos colegas de la Universidad Austral que pudieron salir de Chile, me solicitaron el currículum para llevarlo hacia su destino. Ellos eran Agustín Cullell Teixidó y Víctor Valembois. Ambos viajaron a San José de Costa Rica, porque Agustín tenía familia aquí. Tiempo después, me contaron que, a comienzos de enero de 1974, habían entregado mi currículum y el de otros compañeros a autoridades de la Universidad de Costa Rica. Una de esas personas, con las que se entrevistaron, fue don Isaac Felipe Azofeifa.

En esos momentos -me había saltado un capítulo-, esto es el día 31 de enero de 1974. Días antes yo había ido a ver cómo estaba Muchi y para saber de Carlos Santander en este lapso que me dejaba el toque de queda para 
moverme en Santiago y la que me sale a abrir en la casa de Muchi es Iveth, entonces me dice: "Muchi fue a Valdivia porque tenía que traer unos papeles de los chicos, me dice, y yo me quedé aquí cuidándole la casa", -"Ah bueno" -le digo yo. Entonces yo le dije: "¿No te apetecería salir un ratito antes del toque de queda para que nos sirvamos algo?" -"Bueno" -me dice y ella tenía un Fiat 600 y yo conocía algunas picadas como dicen los santiaguinos, lugares donde hay algo cómodo, que servían unos bocados así como estas galletas, una taza de té o una cerveza. Aprovechamos para conversar entonces, hubo entre los dos una empatía que era el inicio de algo que después se convirtió en más.

De esa manera, cuando yo tuve esta noticia de la llamada de Isaac Felipe Azofeifa, esa misma tarde fui a contarle a Iveth. Entonces, me dice ella: "Bueno, según lo que te diga él, me avisas porque si tienes que ir a alguna parte yo te puedo llevar". Claro, entonces después de la llamada con don Isaac, a las cuatro de la tarde, estaba yo donde Iveth, en la casa de Carlos Santander que seguía en la Embajada y Muchi seguía en el sur de Chile y entonces me dice Iveth: "Mañana a las diez te llevo al Consulado". Y ahí empezó ya esto, empezó una conversación y una necesidad de ambos de estar el uno con el otro porque nos rodeaban las circunstancias más terribles, ella se daba cuenta que la seguían por el hecho de haber salido de la casa donde vivía con sus padres y estar en la casa de Muchi; ello desconcertó a los que la seguían. Estaba bajo sospecha naturalmente, sobre todo si era militante porque las listas de los partidos las tenían ellos. En estas condiciones se produce que vamos al Consulado, yo recibo la carta, ella me dice: "Pero tenés que irte cuanto antes", y yo le digo: "Sí, con una condición: que tú te vengas conmigo" -"No, no puede ser" -me responde. Entonces yo le digo: "Si te lo estoy diciendo como declaración de amor". "Además tu eres casado" -me dice. -"Sí es cierto, yo estoy casado porque en Chile no existe el divorcio. Si hubiera existido el divorcio, yo estaría divorciado, pero no estoy casado". Bueno, pero para ella eso era una cosa bastante inconmovible digamos, pero desde luego, me acompañó, fuimos al cine y yo partí porque tenía, para poder salir del país, que volver a la fiscalía en Valdivia.

Fue una verdadera despedida ahí cuando ella me lleva al autobús en el cual me iba a devolver a Valdivia, nos despedimos como si no nos fuéramos a ver más porque, a todo esto, todos los días sabíamos de la muerte de este, la muerte del otro, la opresión de este otro. Llegué a Valdivia, ahí tuve que hacer trámites por más de 15 días, trámites que pedían de majaderos los militares y había que llegar con orejas gachas y firmar aquí, llevaba uno los papeles y decían le falta el timbre tal, el timbre era los que se llaman aquí esas estampillas de impuestos. "Pero es que no me lo habían dicho" -"Vaya a buscarlo ya". Hasta que ya un día me entregan un papel que dice que aunque estoy en libertad condicional, puedo salir del país por razones laborales.

Porque a todo esto yo había intentado trabajar -no había querido contarles esto-. Mi concuño -como dijiste tú [Carlos Sandoval] que es la palabra que se usa aquí- tenía una camioneta grande y entonces me dijo por qué no... Yo 
puedo meter esta camioneta en la empresa de agua potable -que aquí equivale a Acueductos y Alcantarillados-. Era una empresa muy parecida, muy similar que contrata vehículos o sea compra servicios, vehículos para transportar sus cuadrillas y yo llegué a trabajar un día con la camioneta, hice la fila, presenté mis papeles, los papeles de la camioneta y mi cédula de identidad. -"Tiene que ir a tal lugar ¿conoce usted bien?" -"Sí, sí yo conozco". Yo era de Santiago entonces yo me manejaba muy bien en Santiago; partí con una cuadrilla, los trabajadores atrás yo manejando como chofer de la camioneta y uno al lado que era el capataz conversando normalmente, pero todos sospechando de quién es el otro. Ese clima lo quiero resaltar porque ese era el clima de Chile en 1974. Llegué a mi segundo día me mandaron a otra parte, tercer día me paran en la entrada con la camioneta y me dicen: "Señor, la empresa ha prescindido de sus servicios" -"Pero, ¿por qué?" -"Simplemente le comunicamos que prescindimos de sus servicios" y ahí uno no podía preguntar más. Claro, ¿cuál era mi condición? Libertad condicional. La palabra condicional impedía que te dieran trabajo en ninguna parte porque estabas en libertad, pero condicional. Es como un fatalmente reo futuro o muerto futuro.

Eso fue muy importante porque ocurrió antes del 30 de enero, o sea, había yo hecho el intento de buscar un trabajo, buscar una forma de reinsertarme, yo estaba exonerado, mis hijos no tenían sostenimiento mío. Claro, felizmente su madre estaba bien y estaba en una familia que es de derecha, tenían de todo porque inmediatamente después del golpe aparecieron todos los bienes de consumo que estaban bien, estaban guardados ¿no? Estaban los supermercados abarrotados de cosas.

Vuelvo a Santiago para preparar mi viaje porque ya con los papeles de Valdivia, me presento en el Estadio Nacional que estaba lleno de presos. Estoy hablando del mes de febrero de 1974, estaba lleno de prisioneros todavía el Estadio Nacional y ahí había que hacer la última gestión para que me autorizaran a salir del país. Con el visto bueno de Valdivia, yo ya en Santiago quedaba en libertad para comprar mi billete aéreo y viajar a Costa Rica y salí un día de marzo, creo que era el 9 de marzo o ese fue el día en que llegué aquí porque salimos en la noche con escala en Lima hasta Panamá y en Panamá cambio de vuelo de Panamá a San José.

Yo traía 15 dólares en mi bolsillo, lo único que traía. Y en Panamá me dice la persona de la línea áerea: "Pero usted no tiene el tiquete de salida" -en una variante del castellano que para mí era por primera vez conocida-. Yo creía como que ponía una cara de que me hablaban en inglés, pensando que yo no entendía el castellano, entonces le digo: "Pero, ¿qué es eso?" -"Es que usted tiene que enseñarnos que usted tiene un billete de salida de San José a otra parte. Si no, no le podemos vender el boleto de aquí a San José". 
CS: Ah, es que usted no tenía el boleto.

GG: No, el boleto que me dieron era de Santiago a Panamá, pero en Santiago me aseguraron que yo podía seguir viaje, pero no me dijeron nada de esto que tenía que tener comprado un billete de salida, que el mismo billete que yo traía para llegar a Panamá servía para la conexión a San José. Lo que me faltaba era el billete de salida de San José a otra parte y lo más barato era Managua. Entonces, me dice el panameño -después de que ya nos entendimos- "Sí tendría que tener usted un billete de salida de San José a Managua que vale 30 dólares". Yo me quedo así atónito y había detrás de mí -no me había dado cuenta yo- una señora joven que me dice: "¡Gastón! ¿no te acuerdas de mí? Yo soy Montse". -"Montserrat -le digo yo- sí claro que me acuerdo". Era hija de los que llegaron en el barco francés llamado Winnipeg [en el que republicanos o comunistas habían huido de España y arribaron a Valparaíso Chile en 1939, una iniciativa de Pablo Neruda y el embajador republicano Rodrigo Soriano Barroeta-Aldamar], ella nació en Chile al igual que yo. Y me dice: "Yo voy a San José, me di cuenta de que no tienes el tiquete de salida, pero, mi esposo, que está esperándome aquí en Panamá, te puede prestar el dinero porque él es chileno y él está trabajando en la Universidad de Costa Rica". Raúl Becerra, el esposo de Montserrat, trabajaba en el Semanario Universidad. Yo no tenía idea por qué había perdido de vista a esta mujer durante tantos años.

Becerra me pasó el dinero que me faltaba, compré el famoso tiquete y seguí vuelo con ellos para acá. En San José, Becerra me dice: "Te podemos llevar a algún sitio" -"Claro -le digo yo- me dieron la dirección de Víctor Valembois. Esta es la dirección que traigo porque Víctor Valembois fue profesor en la Universidad Austral y está aquí". "Ah sí - dice Becerra-. Se vé que ya lo había conocido a Valembois. Entonces me lleva a la casa de Valembois, quien sale y me dice con las manos en la cabeza: "Es que ya no te tengo espacio -me dice Valemboisporque llegó ayer otro chileno que es pariente de mi mujer". Él es belga, pero estaba casado con una chilena. "Entonces, no tengo donde tenerte, pero Álvarez de Araya te puede.... - “Está Álvarez de Araya aquí? -le pregunto. Entonces me dice Becerra: "Yo sé dónde vive Álvarez de Araya", vivía en un edificio que hay al lado de la librería Nueva Década, al lado de la Municipalidad.

CS: Unos apartamentos.

GG: Unos apartamentos, vivía en el tercer piso Álvarez de Araya entonces ahí llegamos con Becerra. El avión ese había llegado como a las siete de la mañana de San José. Álvarez de Araya iba saliendo hacia la "U" porque estaba él tratando de conseguir trabajo. Él tenía dos llaves porque esperaba a su mujer, él estaba casado con una rusa. La mujer era profesora en la Facultad de Física de la Universidad de Chile, pero no había salido de Chile todavía, a pesar de que era rusa no le había pasado nada porque pasaba como profesora académica, por tanto, podía pensarse que era disidente de la Unión Soviética entonces... El asunto es que Álvarez de Araya me dice: "Tienes que irte, ya que 
está Raúl aquí, que te diga dónde te compras un colchón y lo metes aquí en este cuarto y ahí va a ser tu cuarto". Becerra me dice: "Sí es aquí en BILSA -creo que se llamaba una tienda que estaba en San Pedro.

CS: Sí, al frente de la iglesia católica de San Pedro.

GG: Sí, ahí compré un colchón y me fui con él al hombro. Ya Becerra se fue a lo suyo, había llegado su mujer con un crío pequeño y me dice: "Ya te dejo" -"Sí hombre sí". Yo con un colchón, la llave, subí al tercer piso y por fin una casa y como al mediodía me rasuré como pude y me fui me fui a la UCR a buscar a don Isaac Felipe y le digo: "Don Isaac, llegué". Y me dice: "Ah qué bueno, tienes clases a las 6" -me dice don Isaac.

CS: ¿De ese día?

GG: Sí, me dijo: "Tienes clases a las 6 de hoy en Estudios Generales". Por el momento estamos cubriendo tu horario completo porque las clases habían comenzado hacía más de una semana.

CS: ¿Eso era febrero?

GG: Era marzo.

CS: Marzo.

GG: Yo llegué el 9 de marzo, creo. Quería hablar justamente de que mi inicio en la Escuela de Estudios Generales fue digamos el punto de partida para que, a pesar de que no existía amistad entre ellos, Isaac Felipe Azofeifa hablase con Jézer González, quien era en ese momento subdirector de la Escuela de Filología, porque el Director de la Escuela de Filología era el señor Víctor Manuel Arroyo, que estaba muy mal... Y yo lo fui a saludar a su casa; él tuvo la amabilidad de recibirnos, pero él estaba ya en proceso final de su enfermedad, tanto es así que, terminando el año 1974, el doctor Arroyo falleció. Pero Jézer González recordaba que le había dicho pocos días antes de morir que era muy importante que tratara de que Gaínza trabajase en Filología porque él se había enterado de la conversación que tuvimos de que yo, por ejemplo, traía muy fresca de Chile la experiencia de la dialectología y aquí no se hablaba nunca de eso porque la Lingüística que se estudiaba aquí estaba más bien dentro de la escuela estadounidense y en ese momento el 'boom' era Chomsky. Para quienes manejaban el campo de la Lingüística aquí no había interés en cosas como la dialectología que consideraban en el borde con lo que los naturalistas estadounidenses llaman el mentalismo, el estudio de los lenguajes en la historia. Entonces, Jézer González pensó que era bueno tenerme a mí para que me hiciese cargo del curso de "Español de América" y luego "Español de Costa Rica". Efectivamente, uno de los primeros trabajos que elaboré aquí es un estudio de algunos fenómenos concretos del castellano hablado en Costa Rica.

Valga la pena resaltar que yo suelo decir castellano y no español porque más bien el término español lo generalizaron los estadounidenses, los lingüistas 
estadounidenses. En realidad, es muy arrogante porque en España no hay un solo idioma, hay por lo menos cuatro idiomas que tienen tanto derecho como el castellano como son el catalán, el gallego portugués, el vasco e, incluso, se habla del bable asturiano que serían también lenguas españolas, pero la arrogancia de los castellanos que... que además les faltaba solamente eso, que los estadounidenses le dijeran español para que ellos se apoderaran rápidamente del idioma y del nombre del idioma.

En el año 1975, empecé tiempo completo en Filología a pesar de que me prestaban para uno o dos cursos a Estudios Generales. Desde luego ya mi nombramiento fue definitivamente en Filología a partir del año 1975 y esto fue así hasta 1984, pero yo cesé toda relación con Estudios Generales en 1978. Es un año para mí muy significativo el 78 porque es el año en que fundamos la revista Escena.

Víctor Valembois, Juan Catevas y yo fundamos Escena. Yo fui el primer editor de la revista, bueno fui el editor de la revista todos estos años hasta cuando yo renuncié a la revista que fue en el 2012 que se vencía mi nombramiento como director de la revista. Escena no era de la Vicerrectoría de Investigación, sino que era de la Vicerrectoría de Acción Social porque en el momento en que se funda, se funda como Escena, como una especie de boletín en torno al Teatro Universitario, que era un organismo que no pertenecía a la Escuela de Artes Dramáticas, que estaba recién fundada, sino que era un organismo de la Vicerrectoría de Acción Social porque era de acción de la universidad, esto hizo que la revista quedase anclada ahí. Entonces esa revista se fundó de esa manera y aunque era semestral había que juntar el material para cada volumen y había que andar rogando a los colegas que colaborasen, es una historia fascinante. Primero la sacamos como un boletín que se hacía en esos años poligrafiado y ya en 1979 sale impresa por la Editorial de la Universidad de Costa Rica. El primer número propiamente tal de la revista sale en junio del año 1979.

Yo creo que este es uno de los hitos más importantes en mi labor en la Universidad de Costa Rica porque no había ninguna revista así y llegó a tener más de 30 años de vida y era la única que abarcaba todas las artes no verbales, pues las artes verbales tenían su revista que era la revista Káñina de la Escuela de Filología.

Entonces nosotros abarcamos todas las artes no verbales o mixtas como son, por ejemplo, el cine, el teatro, la dramaturgia digamos es literatura, pero el teatro es mixto porque la escena en el teatro usa una serie de lenguajes no verbales. Por eso considero que eso fue significativo en mi estancia aquí.

Hay otros dos hechos que son importantes también en ese aspecto porque mi docencia, como les decía, hasta el año 1984 estuvo centrada en Filología. A partir de 1984, cuando regreso de África, Mario Zeledón me insta a que colabore medio tiempo con Ciencias de la Comunicación Colectiva y ahí fue cuando empezamos a conocernos, Carlos y yo. 
Incluso ya pensionado, la Escuela de Ciencias de la Comunicación Colectiva me hizo el honor de que diese, levantándome los requisitos, unos cursos en la maestría inicial en la Escuela. Cuando se iniciaba porque no había en ese momento alguien que asumiese la práctica semiótica digamos, la semiótica aplicada. Sobre todo porque los estudiantes de la maestría de Ciencias de la Comunicación eran de otras carreras en su mayoría. No tenían ni idea, no habían oído hablar nunca de semiótica. Entonces me acuerdo que Patricia Vega fue una de las que impulsó que yo pudiese dar uno o dos años. Estuve al comienzo de la maestría de Ciencias de la Comunicación, ya estaba pensionado yo, pero, de todas maneras tenían que levantarme el requisito porque yo aparecía siempre como licenciado porque ese es el grado que yo obtuve, no pude obtener el otro, ya eso lo escucharon ustedes, porque no pude terminar de escribir mi tesis.

Les decía que la docencia termina toda ahí hasta el final, hasta pensionarme en la Escuela de Filología y en la Escuela de Ciencias de la Comunicación Colectiva. En Ciencias de la Comunicación Colectiva no estuve vinculado a ninguna de las ramas de la Comunicación Colectiva, sí desde la semiótica, la disciplina que más estudiaba yo en ese tiempo, de la que menos ignorancia tenía, digamos. La semiótica ayudaba a todos, fueran periodistas, fueran comunicadores sociales; para todos la semiótica era importante y creo que para las Ciencias Sociales es fundamental, pero ese es otro cantar.

El asunto es que hay otro momento significativo en todo este periodo que va desde el año 1975 hasta el año 1993 o 94 cuando yo me pensiono.

CS: ¿Se pensiona en 1993?

GG: Sí, me mantengo en la universidad o sea el pensionarme no significó que yo me alejase, todo lo contrario tenía más trabajo pensionado que antes de pensionarme. Habían quedado pendientes muchos trabajos de graduación que yo dirigía, que había que seguir y todo eso me mantenía vinculado. Pero hay, les decía, un cambio muy importante. Yo regreso de Costa de Marfil 1984, y me encuentro con otro país. Si no lo han leído todavía lean mi trabajo que se llama "Pespuntes Semióticos II". Digo que efectivamente, al regreso de África, Costa Rica cambió para mí, o sea, me sentí muy, muy, muy mal.

CS: Gastón, ¿podríamos hacer un regreso? Porque no nos ha relatado cómo usted se va a África.

GG: Ah bueno, ¿no les dije eso?

CS: No. Entonces para comprender un poco el regreso.

GG: ¡Claro! En el año 1973, cuando yo caigo prisionero, cuando me hacen prisionero, me entero que Carlos Santander se ha asilado en la Embajada de Italia y antes de partir a Costa Rica logré hablar por teléfono en Santiago con Carlos Santander en la Embajada de Italia y nos despedimos. Yo salgo a 
Costa Rica, no sé si nos volveremos a ver, era el amigo más entrañable que yo tenía, que yo tuve.

Entonces, nunca más supimos nada; la que sabía era Iveth porque, como prima hermana de la mujer de Carlos Santander, se comunicaba con su prima. Ellos salieron al exilio a Francia y Carlos encontró trabajo en la Universidad de Lyon. En el año 1982, sorpresivamente, ahí por comienzos del año, marzo o abril, me llega una carta de Carlos Santander desde África. Carlos me saluda como si nos hubiéramos visto la semana anterior: "Te esperamos porque aquí yo presenté tu nombre y hay absoluta anuencia en que vengas" -"Bueno, voy para allá entonces". Después de tragar litros de saliva, le di la carta a leer a Iveth, entonces ella me dice juiciosamente: "¿Por qué no hablas primero que nada con tus directores? Mira, es importante a lo mejor eso nos favorece a todos porque vas a tener una experiencia que a tu vuelta, me dijo Jézer González, entonces Director de la Escuela de Filología. Tú tienes derecho a pedir permiso sin goce de salario hasta por dos años. Ahora yo te recomiendo que hables con el Rector" -que era en ese momento Fernando Durán Ayanegui. -"No, usted tiene derecho a dos años de permiso que le tramitaría el Concejo Universitario sin problema" -me comenta el Rector. Con todas esas noticias comenzamos a sacar cuentas con Iveth.

El contrato inicial que me ofrecían como profesor invitado era por dos años o sea venía justo. Y respondía a Carlos rápidamente, las cartas se demoraban enorme cantidad de tiempo; ahí por mayo o junio Carlos me responde y me dice: "Mira, ya vamos a salir a vacaciones aquí porque era junio, nos vamos a España de vacaciones, pero tú tienes que estar aquí en septiembre no te preocupes más". Entonces yo saqué las cuentas: septiembre era un momento malo aquí porque el año académico era al revés, el año académico aquí es igual que en Chile, pero distinto de Europa, porque allá empieza en septiembre y termina en junio.

Saqué mis cuentas y arreglé las cosas de manera que efectivamente logré salir de aquí a comienzos de octubre y llegué a Abiyán, la sede del gobierno, donde estaba la universidad nacional, la única que tenían ellos, la Universidad Nacional de Costa de Marfil. Carlos me estaba esperando.

El hecho es que ahí me recibe el embajador que allá era como el gerente mayor del Banco Lehman Brothers. Todos vestidos de una manera occidental, pero extravagantemente...

CS: Miméticamente identificados con los colonizadores.

GG: Era así, me entregaron los papeles, nada más para entregarme unos papeles y que me presentase en el Ministerio de Relaciones Exteriores, para que mostrase esos papeles que me habían dado ellos ahí en París.

Cuando llegué a Costa de Marfil, Carlos primero me contó su historia. Él tenía sus clases en Lyon y llegaban muchos marfileños a estudiar Filología 
curiosamente entonces. Uno de ellos se embelesó con las clases de Carlos; -"Tú tienes que venirte a Costa de Marfil, -le dijo yo voy a ser el director de no sé qué unidad y ya te puedo decir que te vamos a pagar...". Claro, eran francos que se llamaban francos de la comunidad francesa africana. Pero, traduciéndolos a francos de Francia le estaban ofreciendo 3 500. Carlos ganaba 1000 francos en Francia. Simplemente Carlos le dice: "No, no, yo encantado déjame arreglar mis cosas aquí y nos comunicamos". Entonces, de esa manera, parte Carlos a allá. El primer año solo y el segundo año se lleva a la prole.

Yo me voy el primer año solo también porque Carlos me hace ir y caí bien felizmente, como dicen los versos de Sabina, Halló a otro ángel caído de pie. El asunto es que sí, la experiencia mía fue tan grata, tenían ellos una revista, Anales, y ahí quedó un artículo mío que es sobre Mamita Yunai porque uno de los cursos que di fue sobre Mamita Yunai. Yo era costarricense allá, figuraba como costarricense porque era profesor de la Universidad de Costa Rica y porque no quería ninguna vinculación ni con Chile ni con una España, que estaba convulsa, porque era una España en que estaba recién el fin de la dictadura. Yo quería quedarme libre de cualquiera relación, costarricense me sentía a gusto.

En resumen, cuando llega el momento del segundo año, me llevo a Iveth y a Gonzalo para el segundo año. A Iveth le consiguieron trabajo en Biología, en la Escuela de Biología y también ella llevaba un repertorio extraño para ellos de la flora de aquí. Como ella es botánica, entonces la flora costarricense les llamaba la atención. Ella aprendía también como yo, aprendíamos todos los días como locos con una cantidad de cosas.

Y llegó el momento que terminaba ese segundo año y, con toda seriedad, el Decano me dice: "Gastón, tienes que quedarte, eres fundamental, tienes que quedarte" -"No" -le digo yo. Habíamos visto dos cosas fundamentales: no existía seguro social y para cualquier enfermedad tenías que ir a una clínica de los franceses, no a la clínica de los africanos porque los africanos consideraban que un blanco en su clínica era un 'petit blanc' o sea un blanquito, un indeseable y para entrar en la clínica francesa te cobraban la primera pisada, la ponían en la factura; un esparadrapo tanto, el gramo de alcohol que usaron, digo el centilitro de alcohol, todo, todo se especificaba.

Sacamos la cuenta con Iveth, todo esto porque Gonzalo se cayó jugando a la pelota y se hizo una ramilladura [raspón en el castellano de Costa Rica], entonces, mejor que lo vea el médico en la clínica francesa y nos costó un ojo de la cara. Esa fue una experiencia, la primera experiencia.

Y la segunda es que por abril de 1985, habiendo terminado el semestre prácticamente, había detenciones masivas y supimos que cerca de la casa en que vivíamos nosotros había una especie de gran recinto militar que ahí tenían 
hacinados a montones de presos, de prisioneros que los acusaban de ilegalidad, en fin. Había malestar, había malestar.

El problema se agrava en África porque las personas pertenecen más a una cierta etnia y en segundo lugar a una cierta localidad. En África, antes que ser marfileño, eres de Abiyán. En Costa de Marfil hay 72 idiomas, no dialectos de un idioma, sino 72 idiomas distintos, como lo he dicho en algún articulejo, tan distintos como el castellano del árabe o sea que entre ellos no se entienden. Ninguna de esas lenguas tenía escritura; en aquellos años de 1982, 1983, 1984 se estaba trabajando en la gramática de los mandingas; etnia que tenía protagonismo en el comercio y por eso su lengua era conocida.

Los problemas que se estaban presentando tenían que ver también con la repartición de los territorios que hicieron los europeos en África, por ejemplo hacía un límite que cortaba a una comunidad étnica y la dejaban en dos países distintos, o en tres. Poco antes dijimos con Iveth, no, tenemos que volver por la seguridad de Gonzalo. Gonzalo había aprendido el idioma porque él hizo primer año de primaria en francés con sus compañeros, eran tres blancos en el curso, un curso de 35 rapaces, eran tres blancos. Gonzalo era el menos blanco porque los otros eran franceses. Entonces, Gonzalo era el adorado por los otros niños, porque los negros no querían a los franceses. Cuando un colega profesor supo que yo tenía una hija, escribió un poema para ella, en castellano: No te puedo escribir en mi idioma porque mi idioma no tiene escritura, ni quiero escribirlo en francés porque todavía en las espaldas de mi abuelo están las huellas del látigo de los franceses. Todo eso yo lo iba aprendiendo.

Cuando llegó el momento de: "Se tienen que quedar ustedes", con mucha diplomacia además, con mucha amabilidad afectuosa, afectuosamente, yo tuve que hablar con claridad y decir: "Tenemos muchos deseos de quedarnos, pero, creemos que en este momento el país, nuestro país, Costa Rica, también nos necesita y creemos que por Gonzalo que tiene una tradición afincada, él es costarricense en plenitud, tenemos que volver; eso no quita que más adelante podamos intentar otro...". Bueno, hubo una suerte de solución salomónica. Carlos me dice: “¿Pero, por qué te vas a ir?”. Y le digo: "Mira, yo nunca como profesor he ganado tanto como en mi estancia aquí, pero no creo que sea ese el sentido de mi vida tanto así que te voy a decir yo no me voy a cansar de hacer todo lo posible por llevarte a Costa Rica". Mis palabras fueron proféticas porque ese año, 1984, a fines del año, se produce un gran movimiento social que es reprimido violentamente por el ejército, el cual, igual que todo el país, estaba formado por etnias distintas, entonces entre ellos no había uniformidad y la Guerra Civil estalló a fines del año 1985. Y alcanzamos a sacar a Carlos en julio de ese año. Carlos llegó aquí como profesor en el segundo semestre, en la Universidad Nacional y en la Universidad de Costa Rica.

Pero, entonces vuelvo a lo que les estaba diciendo antes, Carlos, que mi regreso a Costa Rica en 1984 es un regreso traumático porque ha cambiado 
todo en Costa Rica. Entre septiembre de 1982 y agosto de 1984, habían pasado casi dos años y en esos dos años habían empezado todos los planes de ajuste estructural, el gobierno del señor Monge (1982-1986) había agudizado la contradicción contra el problema de Nicaragua, pero, sobre todo, eran los planes de ajuste estructural exigidos por el Fondo Monetario Internacional, lo de siempre. Como dice Naomi Klein en el libro titulado La doctrina del shock, el laboratorio fue Chile, porque Chile cambia al neoliberalismo en el año 1973 de un sablazo, nunca mejor dicha la metáfora. Aquí también los rebotes empiezan a llegar en 1982, 1983. Se había producido la devaluación de la moneda, eso fue también horrible, la cantidad de emigrantes que ya huían de las guerras en El Salvador y Nicaragua. Todo eso traía consigo una inestabilidad muy notable.

A raíz de eso se crea en la Vicerrectoría de Acción Social un seminario que se convierte en programa, en un programa de Acción Social que preside en ese momento un arquitecto, no me pregunten el nombre porque no me voy a acordar. En ese programa se presentaban pequeños proyectos, nos reuníamos semanalmente, una vez a la semana, en la Vicerrectoría. De ese programa surgen dos iniciativas: la revista Herencia, cuyo primer número empieza a circular en el año 1989 y el Programa de Identidad y Cultura Latinoamericanas, que se crea en la Facultad de Filosofía y Letras, por iniciativa fundamentalmente de María Salvadora Ortiz, quien era profesora en San Ramón en la Sede de Occidente y Álvaro Quesada, quien era el titular de literatura aquí en la Sede Rodrigo Facio.

El programa se elabora en el año 1988 y entra en vigencia, con varios programas en el año 1989. Nuestra voluntad se cumplió, que fuera multidisciplinario desde la partida, que abarcara ojalá todas las Ciencias Sociales, aunque tuviera su origen en la Ciencia literaria digamos. Surgen esas dos cosas de manera que yo me convierto en co-fundador de la revista Herencia y de este Centro de Investigación en Identidad y Cultura Latinoamericanas. Por eso me mantienen aquí. Si no, no tendría que estar aquí pero, no quieren que el abuelo se vaya, me conservan por eso. Yo quiero terminar con esto...

CS: Gastón, perdone otra interrupción.

GG: Sí, sí.

CS: Algo que a mí no me termina de calzar ¿cuándo usted hace... si se pudiera decir así, como el giro de la lingüística a la semiótica?

GG: Ah muy importante eso, jclaro! Eso es muy importante.

CS: Porque yo lo tengo claro, pero no identifico la transición.

GG: ¡Claro! Yo tuve... dentro de los profesores en Madrid, aparte de Rafael Lapesa tuve otros profesores entre ellos, Eugenio Coseriu que era un lingüista, un profesor fascinante, el rumano ese, hablaba castellano perfectamente. Él no era marxista, pero sabía que no podía alejar la lingüística del materialismo histórico, él sabía eso. Nos dio a leer a Adam Schaff y cuando yo regreso a Chile, 
estoy hablando del año 1968-1969, sigo buscando el tema en las librerías de Santiago. Cuando yo iba de Valdivia a Santiago me pasaba un día entero en la Librería Universitaria y encontraba siempre materiales novedosos que trataban, enfocaban el estudio del lenguaje como estudio de los lenguajes; cosa que en su momento había dicho Saussure a fines del siglo XIX o Peirce, en Estados Unidos, pero, él era mucho más desconocido para nosotros en Chile. Saussure sí era una fuente importante, pero, nunca se había enfocado de una manera como lo estaban haciendo Schaff y otros que alcancé a leer entonces. Schaff es el que tengo más claro. Por la revista de Casa de las Américas también leo, por ejemplo, al italiano Feruccio Rossi Landi. Cuando llego a Costa Rica sigo en ese plan, pero, tengo que ofrecer el curso Español de América, que no me significaba ninguna dificultad. Salieron tesis; dirigí tanto tesis aquí en la Universidad de Costa Rica como en la Universidad Nacional (UNA).

Miguel Ángel Quesada (Premio Magón en año 2014), por ejemplo, dice que yo lo introduje al verdadero conocimiento. Yo creo que es un gran romanticismo de Miguel Ángel, que yo le he agradecido siempre pero que no corresponde; él es mucho más estudioso, es autónomo digamos. Puede que yo lo haya hecho leer cosas como a mí me hicieron leer mis profesores que por eso le llaman maestros y, tal vez, en ese sentido, admito que me lo reconozca. Su primera tesis de él fue conmigo, la de grado. También en la UNA, una tesis de dialectología aplicada, etnográfica, digamos que es el estudio de los ingenios de azúcar y todo lo concerniente a las palabras usadas en el proceso, los nombres, todo y que era comparativa porque se podía comparar con otras regiones de habla castellana que tuviesen también caña porque cambiaban de una parte a otra, como nosotros nos dimos cuenta en Chile, el nombre de todos los productos asociados a la producción de vino con respecto a cómo se decía en castellano en España.

Pero en el año, creo que de 1981, Jézer, quien me había escuchado en una charla hablar de Adam Schaff y cosas así y que yo ya había publicado unos trabajos en que mencionaba a estos autores, me dice: "Te voy a abrir un curso, que vamos a llamar: Tópicos de semiótica. Era el año 1981, este curso se ofrece en la Escuela de Filología, pero, se ofrece también a otras escuelas. Por ahí se entera María Pérez, quien era profesora de la Escuela de Filología.

Mario Zeledón también se entera de que yo estoy dando un curso que se llama Tópicos de Semiótica y me pide intercambio de programas y con gusto le pasé mi modesto programa porque estaba recién comenzando. Pero, ahí tuvo Mario la idea de que, al regresar de África, me tenía que sacar medio tiempo de aquí y llevarme a la Escuela de Ciencias de la Comunicación Colectiva. Fue su intuición y además contaba con el apoyo de María en ese momento que sabía que era más importante en Ciencias de la Comunicación que en Filología.

Puede que haya tenido razón, no sé, pero en todo caso esto es, esto es lo que querías saber tú, esta es la forma en que de pronto ya la lingüística quedó 
relegada. Además, había pasado otra cosa: al volver a África, un profesor había tomado el curso de Español de América, quien lo cubrió bastante bien, pero se enamoró del curso y de manera que cuando yo vuelvo a Filología el que me desligue medio tiempo le queda muy bien a todo el mundo. El medio tiempo que me voy a Comunicación era el medio tiempo de mis cursos de Español de América y Español de Costa Rica, eran dos cursos distintos.

Este profesor ya le había tomado el gusto a eso, cosa que me alegró. Y me quedo entonces con Tópicos de semiótica y otra cosa que daba yo que tenía que ver con epistemología, que era una perspectiva materialista histórica de la epistemología efectivamente, no me acuerdo cómo se llamaba el curso.

\section{CS: ¿Y el encuentro con Bajtín y Voloshinov y este círculo?}

GG: Eso es lo que ocurre fundamentalmente en África. En Costa de Marfil, la biblioteca de la Universidad Nacional, yo no sé si la tomaron como modelo, pero, era igual a la biblioteca que sale en la película de Umberto Eco, El nombre de la Rosa. Había que entrar en una escalera de caracol para entrar a distintos pasillos, era una biblioteca fabulosa la que tenían. Supe que después con la guerra civil que hubo, hubo gran destrucción de todo eso... No sé si vieron la película La sal de la tierra, de Wim Wenders, se las recomiendo. Es la historia de un fotógrafo brasileño que después de fotografiar las catástrofes más grandes, y eso que no ha visto las últimas, porque se murió antes de la migración del norte de África hacia Europa, ni las migraciones a América. Después de fotografiar eso exclama en un rapto ya de desesperación, tiene 70 años de edad y dice: "Esta es la especie peor del planeta, no tenemos derecho a estar vivos".

Un poco eso me hizo recordar lo que pasó con la Guerra Civil en Costa de Marfil, supe que todo había sido saqueado, la biblioteca, todo, todo, una cosa dolorosísima. La experiencia de esa biblioteca me metió entonces en los libros, además los libros que se editaban en Francia llegaban prácticamente al día siguiente, exagerando el tiempo. En ese momento surgen estos nombres que tú señalas, van apareciendo todos, Tzvetan Todorov por ejemplo, y yo los leo en francés. Por otro lado, un iberoamericano, Eliseo Verón, no sé si te acuerdas, quien murió hace poco. Eliseo Verón no escribió nunca más en castellano, él escribió en francés todo, al final le traducían sus libros de francés al castellano porque se afrancesó a tal extremo que para él era más fácil ya escribir en francés que en castellano y tiene un libro fundamental, Verón, yo creo que alcanzamos a tratarlo por esos años de finales de los años ochenta, comienzos de los noventa, titulado La semiosis social.

Que es el primer nombre que yo voy a usar también en mis divagaciones, semiosis social, y que voy a cambiar después cuando leo a Yuri Lotman. Voy a cambiar por semiosfera porque me parece más convincente el nombre de semiosfera que el de semiosis social. Semiosis social todavía tiene mucho halo, un halo idealista; está dentro de la concepción idealista del mundo. En cambio, 
semiosfera, como dice Lotman, lo toma de otro ruso que en 1901 toma la palabra biosfera y que tiene un sentido materialista. Entonces, semiosfera es el lugar donde ocurren todos los discursos y se producen todos los textos que era la idea de Verón, pero que la palabra semiosis social la teñía un poquito al idealismo peirciano, de Peirce. Esa fue mi relación con la semiótica, Carlos.

CS: Y luego..., perdón Gastón que me vaya a los detalles, y luego hay un encuentro con Álvaro Quesada quien había estudiado en la, entonces, Unión Soviética.

GS: Claro, él estudió en lo que ahora es San Petesburgo, Leningrado. Entonces, nos hicimos muy amigos con Álvaro, compartíamos los fines de semana asado y vino. A él le encantaba la cosa del sur, del sur de Sudamérica y hacíamos en la casa de él o de Juan Catevas con la esposa de Álvaro que es la gran actriz Eugenia Chaverri y entonces los hacedores del asado de carne éramos Catevas y yo, uno griego y el otro vasco, pero chilenos porque Catevas era absolutamente griego.

CS: Gastón, otra pregunta a propósito de los temas de actualidad ¿usted intervino en la tesis que si mi memoria no me falla abre la polémica con Cocorí?

GG: La autora era alumna mía nacional, era afroamericana. Su nombre es Lorein Powell y su tesis se titula "Lectura en crisis de tres obras racistas", presentada en 1985.

GG: Parece que falta algo, ya estoy cansado.

CS: Tal vez Gastón, abusando un poquito, si nos puede contar de las experiencias de solidaridad una vez establecidos acá con Chile.

GG: Bueno, creamos un comité naturalmente, un comité de solidaridad integrado por costarricenses y chilenos. En ese comité de solidaridad los integrantes costarricenses muchos eran de Vanguardia, naturalmente, de Vanguardia Popular, de La hormiga [forma coloquial de llamar al Partido Socialista]. Pero, también había gente, como Isaac Felipe Azofeifa, del partido Liberación Nacional, digamos social-demócratas en sentido estricto. Recuerdo yo por ejemplo del tiempo que me tocó estar más activamente, nosotros hicimos aquí un simulacro de los partidos también, o sea nosotros tuvimos nuestro comité regional costarricense del Partido Socialista de Chile, había un comité regional del Partido Comunista chileno.

Reuníamos dinero y se enviaba a algunos puntos específicos de Chile como ayuda, fundamentalmente, ayuda para mantener gente, no para comprar armas ni cosas así, no tenía sentido. Pero, en todos esos actos, este comité integrado, como digo, por costarricenses y chilenos funcionó muy bien hasta yo creo... se produce un gran quiebre ahí en 1979 cuando comienza la Guerra de Nicaragua. En primer lugar, porque se tiene que crear un frente de solidaridad con el Frente Sandinista de Liberación Nacional y, en segundo lugar, porque de aquí parte mucha gente que se fueron a combatir allá incluso chilenos, hijos 
de chilenos; Rodrigo, mi hijo mayor, partió para allá en el Frente Sur. Entonces ahí ya hay otra coyuntura que hasta el año 1979, digamos, este comité funcionó de una manera, como un reloj. Los primeros años de la década de los ochentas, o sea, el año 1981 y 1982 yo me fui a África y era menos.

Incluso los que fuimos mazones en Chile levantamos columnas, como se dice en términos masónicos, aquí y creamos una logia que fue recibida por la Gran Logia de Costa Rica con el nombre de Logia Lautaro como las lautarinas del siglo XIX. Esa Logia Lautaro estaba formada por chilenos y por costarricenses, hubo mazones costarricenses también que se incorporaron en las prácticas nuestras que eran más o menos las mismas porque la mazonería tiene un comportamiento de la fraternidad como se llama en los términos más únicos, universal ¿no? Hay tendencias sí dentro de la mazonería, unas tendencias que son irreconciliables entre sí. La Gran Logia de Chile y la Gran Logia de Costa Rica, por ejemplo, no admiten mujeres. En cambio, hay otra tendencia mazónica en que sí hay mujeres que son mazonas

Mi papel en la mazonería al comienzo fue de infiltrar el papel político mío, no fue de recibir beneficios espirituales como muchos de los que llegan a la mazonería, lo que quería saber era cómo operaban políticamente porque era fundamental en Chile saber eso. Allende era mazón y socialista; en cambio la Logia de Chile, la Gran Logia y las distintas logias dependientes de ella no admitían a un comunista o que hubiese sido un comunista.

Efectivamente adentro era todo igual que afuera lo único que nos diferenciaba es que teníamos posiciones políticas encontradas y nos diferenciaba el que el principio fundamental de la mazonería supuestamente era la tolerancia. Sin embargo, en el año 1973, en Chile, se rompió porque todos los que fuimos mazones estuvimos prisioneros y fuimos expulsados. Algo parecido pasó con la Logia de España tras la Guerra Civil. Entonces nosotros aquí cuando levantamos columna la Gran Logia de Costa Rica, esta Logia Lautaro mantuvo la historia anterior de la Logia chilena, no la posterior porque la posterior era deleznable, la tolerancia se la pasaron por el sobaco simplemente. Incluso había habido una llegada previa a nuestro grupo, los que salieron cuando ganó Allende en Chile y que se instalaron aquí incluso, casi todos tenían mucho dinero, los que vinieron a Costa Rica. Esos, cuando llegamos nosotros, nos repudiaban naturalmente. Éramos los rojos que venían, que los habían hecho huir a ellos; ganó Allende y ganaron los rojos.

Y entonces ellos salieron a distintas partes y llegaron a Costa Rica, pero, curiosamente, con la vuelta de los años ellos han vuelto a lo que fundamos nosotros. Nosotros fundamos una Casa Chile a espaldas de la Embajada, a espaldas del consulado porque la embajada y el consulado eran de Pinochet y naturalmente estos chilenos anti-rojos digamos -los voy a llamar así para economizar- no se metían con la plebe esta con la cual yo había llegado, pero, curiosamente, cuando se instala la pre-democracia, así la llamo yo, todavía es 
pre-democrático Chile, no es democracia. No hay democracia real en Chile mientras no haya un cambio en la Constitución porque la Constitución es la que aprobó el Estado militar y está plagada de errores.

Pero, entonces, como digo, cuando se instalan la Concertación, que es el nombre que le dan a este fenómeno, esta gente que antes no nos podía ver empieza a mezclarse y llegan a la Casa Chile cuando hay actos. La Casa Chile hace un acto en septiembre porque las actividades patrias de Chile igual que en Costa Rica son en septiembre: en Costa Rica el 15 y, en Chile, el 18, entonces hacen unos actos y a mí me gusta ir. Los nietos de los que llegamos ya son del grupo que canta, que baila, que están ahí y hay mixtos, o sea, hay mucho matrimonio tico-chileno entonces todo eso es grato y ahí llegan ya todos estos chilenos, algunos ya murieron naturalmente como también en el grupo nuestro pero ya estamos... aquí estamos mejor que dentro de Chile, es curioso eso.

Y tal vez sea la solidaridad que dices tú, la palabra que lo explica. Después de todo, la experiencia de un exilio es la misma para los de un bando como para los del otro y como lo he descrito el exilio es una ruptura de códigos, sientes que tienes que romper una serie de códigos y adquirir nuevos códigos, un aprendizaje largo que no termina nunca.

*Nota de la Editora: De manera excepcional, Cuadernos Inter.c.a.mbio sobre Centroamérica y el Caribe publica una entrevista. Se trata de un texto que fue sometido a evaluación por pares y se ubica en la sección denominada "Entrevista". Sin pretensión de fundar una sección de entrevistas, se incluye este texto en tanto que representa un relato vivencial que enriquece la comprensión de la temática migratoria, en especial, la del exilio, y porque constituye un homenaje a un destacado académico, el profesor Gastón Gaínza, quien ha aportado de manera notable al quehacer académico e institucional de la Universidad de Costa Rica, incluyendo el Centro de Investigación en Identidad y Cultura Latinoamericanas (CIICLA). 